\title{
Hydrogeological and Climatological Risks Perception in a Multi-Hazard Environment: The Case of Greece
}

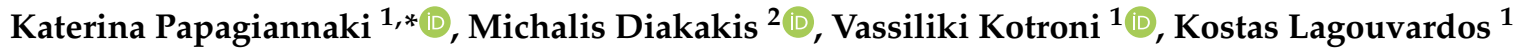 \\ and Emmanuel Andreadakis 2 (D) \\ 1 Institute of Environmental Research and Sustainable Development, National Observatory of Athens, \\ 11810 Athens, Greece \\ 2 Faculty of Geology and Geoenvironment, National and Kapodistrian University of Athens, 15784 Zografou, \\ Greece \\ * Correspondence: katpap@noa.gr
}

Received: 31 July 2019; Accepted: 22 August 2019; Published: 25 August 2019

\begin{abstract}
Climate-related hazards, such as wildfires and hydrogeological phenomena, cause extensive damages and casualties around the world. Despite the recent advances and technologies for risk mitigation, it is acknowledged that public risk perception is a critical factor for these tools to succeed. Greece and the broader Eastern Mediterranean is an area where, despite the diversity of natural disasters, there is a lack of understanding of the hazard types that people are most concerned with and how they measure against other groups of hazards (i.e., geophysical). This work uses an online survey targeting Greek people, aiming to provide a better understanding of their perception of different natural hazards. Statistical results show that people consider climate-related hazards less dangerous and likely to occur than earthquakes, which occur often as zero-impact events. Laymen may thus underestimate certain risks, which may inhibit appropriate preparation. Disaster experience was found to increase threat perceptions and to motivate preparedness. However, in what concerns climate-related hazards, the effect of experience may fade out over time. Awareness activities were found to associate with higher emergency response efficacy. Males exhibit lower risk perception and higher coping appraisals. However, prioritization of risks is almost identical between genders. Implications for risk management are discussed.
\end{abstract}

Keywords: multi-hazard; hydrogeological; climatological; risk perception; Mediterranean

\section{Introduction}

Hydrogeological and other climate-related hazards, such as floods, storms, mass movement, and wildfires, cause extensive damages [1-3] and a noteworthy number of fatalities around the world [4-10]. Between 1988 and 2017, they accounted for US $\$ 2245$ billion or $77 \%$ of the total damage costs amongst all types of disasters [11]. In particular, climate-related hazards' frequency and significance are expected to grow even more, given the adverse climate change projections that predict an increase in flood, mass movement, and forest fire occurrence in parts of the world and in the region [12-14]. Hence, the protection of human life and property from climate-related events as an adaptation strategy to climate change will be of high priority in the near future.

Several new technologies, methodologies, and applications have been used or developed recently, as initiatives or measures (structural or non-structural) to mitigate climate-related risks [15]. The variety of available tools includes early warning and forecasting techniques [16-18], data-driven prediction methods and machine-learning-powered algorithms and modeling techniques $[19,20]$ and risk assessment methods [21], along with a wide range of adaptation measures [22], which have been commonly applied in a large number of countries. Nevertheless, risk perception and understanding of 
natural hazards by the public are considered a crucial piece of the puzzle of dealing with risk, affecting the success of the above applications and advances [23]. Particularly with regard to hydrogeological hazards, where the need for individual preparation and response to prediction and alert systems is of the utmost importance, a major challenge for risk management is to understand the factors that drive precautionary behaviors. This is why the perception of risk has been widely recognized as a crucial element in flood risk management, leading to a gradual integration of social aspects with more conventional risk estimation methods $[24,25]$. The same applies to geophysical hazards, such as earthquakes and volcanos, for which the perceptions and views of society affect protective actions and information seeking, as well as the effectiveness and success of risk mitigation programs [26-28]. In addition, perception of risk by the general public can be considered a key driver of the public agenda, and eventually influences how government policies are shaped to increase resilience and mitigate risk [29]. This is particularly crucial in multi-hazard environments, where the capacity and the expertise of civil protection organizations is tested in diverse prevention efforts, often in very different types of natural hazards.

The importance of public perception, especially with regard to hydrogeological hazards, is reflected in the growing number of relevant studies carried out in the recent years [30,31], focusing mostly on areas of Europe and the Americas. These studies explore the perception of likelihood and significance of the impacts of future disasters [25,32-39] and the effect of disaster experience and risk communication on individual's perceptions and precautionary behaviors [40]. They also study the awareness and knowledge of individuals on hydrogeological hazards [25,37,41,42], adoption of self-protection measures and preparedness actions [41,43,44], trust in institutions [35,42], as well as emotions affecting the degree of preparedness against risk [32,36,37,42]. Furthermore, several studies examine the demographic characteristics of the surveyed populations, mostly as predictor elements of overall views, knowledge, and stance against hydrogeological risks [37,45-49]. Empirical studies have shown that risk perception varies by type of environmental risk [50,51].

Despite the increasing number of perception studies, there is limited understanding of how laymen perceive and view different types of climate-related hazards against geophysical hazards, in areas where they are all present at a significant level [52,53]. In addition, it is not clear whether the public focuses or is biased against certain types of hazards and how their level of knowledge, coping appraisal, priorities, and feelings compare between different hazard types. The Mediterranean region is a key area to investigate the above topics, due to the persistence of occurrence and the high levels of risk of both climate-related and geophysical hazards and the extensive impacts of previous disasters, which indicate that communities have rich experiences of a variety of hazards.

In this context, and given the limited understanding of perception in the region [54], this work aims to explore laymen's perception and views on hydrogeological and other climate-related hazards against geophysical hazards in Greece, as a characteristic case of multi-hazard environment. The study aims to:

1. Provide a basic understanding of how the different types of natural hazards compare with each other in terms of risk perception, feelings of worry and coping appraisals,

2. Identify possible shortcomings or differences in awareness of the public,

3. Assess patterns on their stance in terms of precautionary behaviors and confidence attitudes,

4. Identify possible links among the above awareness/behavioral variables, including demographic attributes, to address practical implications for risk management.

\section{Materials and Methods}

\subsection{Survey}

In this study, we investigate the views and perceptions of nine natural hazards commonly occurring in the region: Three hydrogeological (floods, storms, and mass movement) and other four climate-related hazards (heatwaves, frost, drought, and wildfires), against two geophysical hazards, 
i.e., earthquake and volcano eruption. The target group was the entire Greek population so as to capture the general public's view on natural hazards' risk.

To this end, we constructed and launched a 30-question online web-based survey questionnaire, gathering a nationwide sample of 2330 respondents through the website www.meteo.gr. This website provides weather observations and weather, wave, lightning, and dust forecasts and alerts produced by the weather forecasting group at the Institute for Environmental Research, National Observatory of Athens (IERSD/NOA) [55-58]. Most importantly, it is the most trusted Greek meteorological website and among the five most visited ones of general interest in Greece. The average number of daily unique visitors to the website exceeds 350,000 . Surveys related to weather hazards have been systematically posted with a very strong public response [40,59].

The questionnaire was posted online on 28 January 2019 and was active for four days. It aimed to examine laymen risk perception, experience, and awareness of each natural hazard risk for themselves and their properties. Participants were also asked questions about the implementation of precautionary measures, their coping appraisal and trust in the official risk management and the various sources of information. It was structured in the following order:

- Section 1 introduced the purpose of the survey.

- Section 2 included threat perceptions (risk perception, worry, and perceived likelihood of occurrence) for each of the nine natural hazards. The order of the hazards was random, that is, independent of their type, to avoid systematic responses.

- Section 3 included disaster experience.

- Section 4 included precautionary measures and the resulting capacity to cope with risks, as well as insurance coverage.

- Section 5 included awareness and trust in warnings and risk management authorities.

- Section 6 included individuals' perception of their emergency response efficacy and their capacity to meet the financial needs to cope with risks.

- Section 7 included residential status, municipality of residence and demographics. Participants were asked about their gender, their age and income level, their professional and family status.

The respondents were required to answer each survey question. However, few questions were filled only upon criteria (e.g., if a previous question was positively answered). The type of the survey questions was closed-ended questions: Rating scale (Likert-type scales and semantic differential scales), multiple-choice questions, dichotomous and demographic questions. The entire questionnaire, including the type of survey questions, is available as a supplement to this work.

\subsection{Sample Profile}

Table 1 provides a summary of participant demographics compared to the Greek population demographics. Compared to the last national census in 2011, males are slightly overrepresented (56\% of the sample). Ages between 25 and 55 years old are overrepresented in the sample ( $78 \%$ compared to the $51 \%$ in the census), while people over 65 years old are underrepresented ( $3 \%$ compared to the $23 \%$ in the census). These percentages probably reflect the low use of the internet by the elderly. The average education and family income levels are both higher among the survey population. The rate of home ownership $(76 \%)$ is very close to the census data $(74 \%)$, while the rate of unemployment $(15 \%)$ is slightly lower than the country's unemployment at the time of the survey (approximately $18 \%$ ). The geographical distribution of the survey respondents at the regional level is representative of the population census distribution. The highest share (39\%) of the respondents lives in the most populated region, Attica (35\% in 2011 population census). 
Table 1. Comparison of survey demographics to the Greek population.

\begin{tabular}{|c|c|c|}
\hline Demographic Characteristics & Sample (\%) & Greek Census 2011* $(\%)$ \\
\hline \multicolumn{3}{|c|}{ Gender } \\
\hline 1: Female & 44 & 51 \\
\hline 2: Male & 56 & 49 \\
\hline \multicolumn{3}{|c|}{ Residential status } \\
\hline Homeowner & 76 & 74 \\
\hline Renter & 24 & 26 \\
\hline \multicolumn{3}{|c|}{ Age level } \\
\hline 1: $15-24$ & 10.0 & 12.8 \\
\hline 2: $25-34$ & 20.3 & 16.7 \\
\hline 3: $35-44$ & 33.6 & 17.8 \\
\hline 4: $45-54$ & 24.0 & 16.0 \\
\hline 5: 55-64 & 9.3 & 13.9 \\
\hline $6: 65-74$ & 2.5 & 11.4 \\
\hline $7:>75$ & 0.3 & 11.4 \\
\hline \multicolumn{3}{|c|}{ Education level } \\
\hline 1: Primary school & 1 & 29 \\
\hline 2: Secondary school & 19 & 39 \\
\hline 3: Technical schools & 18 & 13 \\
\hline 4: Bachelor degree & 41 & 18 \\
\hline 5: Master/PhD degree & 21 & 2 \\
\hline \multicolumn{3}{|c|}{ Family income level } \\
\hline 1: $<10,000$ euros & 32 & 67 \\
\hline 2: 10,000-20,000 euros & 40 & 23 \\
\hline 3: $20,000-40,000$ euros & 22 & 8 \\
\hline 4: $>40,000$ euros & 6 & 1 \\
\hline \multicolumn{3}{|c|}{ Family status } \\
\hline 1: Unmarried & 38 & 43 \\
\hline 2: Married & 37 & 11 \\
\hline 3: Parent & 25 & 47 \\
\hline \multicolumn{3}{|c|}{ Employment status ** } \\
\hline Unemployed & 15 & 18 \\
\hline Employed & 67 & 41 \\
\hline \multicolumn{3}{|c|}{ Geographical distribution per administrative region } \\
\hline 1: Attica & 38.6 & 35.4 \\
\hline 2: Central Macedonia & 20.2 & 17.4 \\
\hline 3: Crete & 5.9 & 5.8 \\
\hline 4: Thessaly & 5.6 & 6.8 \\
\hline 5: Peloponnese & 5.5 & 5.3 \\
\hline 6: Western Greece & 5.4 & 6.3 \\
\hline 7: Eastern Macedonia and Thrace & 4.7 & 5.6 \\
\hline 8: Central Greece & 3.7 & 5.1 \\
\hline 9: Epirus & 2.8 & 3.1 \\
\hline 10: South Aegean & 2.1 & 2.9 \\
\hline 11: Ionian Islands & 2.1 & 1.9 \\
\hline 12: North Aegean & 2.0 & 1.8 \\
\hline 13: Western Macedonia & 1.6 & 2.6 \\
\hline
\end{tabular}

* 2011 General Censuses, Greek Statistics Agency, http://www.statistics.gr/. National population census takes place every 10 years. ${ }^{* *}$ Census data are average annual rates (Greek Statistics Agency 2017). The employment rate is the percentage of employed in the total population. 


\subsection{Analysis Methods}

Responses to Likert-scale questions are coded on a five-point scale, where, in general, 1 means "disagree" and 5 means "strongly agree". Categorical variables such as education, income, and age level are treated as continuous. Binary variables are produced from responses related to the experience of natural hazards, to the purchase of insurance coverage for natural hazards, and to the implementation of predefined precautionary measures. A new continuous variable is generated from the summation of the binary items of implemented precautionary measures, so as to measure the level of individual preparedness against natural hazards. The detailed questionnaire structure is provided in the supplementary material.

To investigate the survey responses, we employed several statistical methods. Descriptive analysis and non-parametric tests were used to check for the distribution of the survey variables and the correlations between them. Spearman's rank correlation method is applied, because it does not assume normality of data and is appropriate for correlating both continuous and discrete variables $[60,61]$. Chi-square test is applied to test the correlation between categorical and ordinal or continuous variables. The Wilcoxon signed rank test is applied to estimate whether continuous or ordinal variables, such as risk perception and preparedness, are significantly different among the survey groups with different demographic characteristics or prior experiences. Kruskal-Wallis $\mathrm{H}$ test is applied when the independent variable consists of more than two groups. Statistical analyses were assisted by computer software STATA. The level of confidence of all statistical analyses was $5 \%$, as proposed in similar studies [62].

Finally, based on theoretical and empirical models of protection motivation processes [40,44,63], we developed a cognitive map of the resulted relationships among the set of the examined variables to investigate the paths linking risks perceptions and coping appraisals with awareness, confidence and preparedness against climate-related hazards. Demographic attributes are also included in the analysis.

Due to the large volume of variables, detailed statistical results, as well as the coding and specifications of the variables are provided in Appendix A of this article.

\section{Results}

\subsection{Threat Perceptions}

Participants were asked about their overall perception of the importance of the said risks, the worry they feel about each of them, as well as their view of the likelihood of each hazard's occurrence. Table 2 shows the descriptive statistics for the three variables of threat perception: Risk perception, worry, and perception of the likelihood of occurrence of each hazard. 
Table 2. Descriptive data for the variables of threat perceptions.

\begin{tabular}{|c|c|c|c|c|c|c|c|}
\hline \multirow[t]{2}{*}{ Hazard Type } & \multicolumn{3}{|c|}{ Risk Perception } & \multicolumn{2}{|c|}{ Worry } & \multicolumn{2}{|c|}{$\begin{array}{c}\text { Likelihood of } \\
\text { Occurrence }\end{array}$} \\
\hline & Obs & $\mathbf{M}$ & SD & $\mathbf{M}$ & SD & $\mathbf{M}$ & SD \\
\hline \multicolumn{8}{|c|}{ Hydrogeological and climate-related hazards } \\
\hline Flood & 2330 & 3.13 & 1.21 & 3.24 & 1.12 & 3.46 & 1.22 \\
\hline Storm & 2330 & 2.95 & 1.13 & 2.95 & 1.08 & 4.36 & 0.85 \\
\hline Mass movement & 2330 & 2.64 & 1.22 & 2.97 & 1.19 & 2.64 & 0.95 \\
\hline Heatwave & 2330 & 2.91 & 1.10 & 2.58 & 1.08 & 4.27 & 0.89 \\
\hline Frost & 2330 & 2.78 & 1.21 & 2.75 & 1.18 & 3.34 & 1.30 \\
\hline Drought & 2330 & 2.81 & 1.15 & 3.06 & 1.20 & 3.37 & 1.16 \\
\hline Wildfire & 2330 & 3.49 & 1.34 & 4.08 & 1.05 & 3.58 & 1.37 \\
\hline \multicolumn{8}{|c|}{ Geophysical hazards } \\
\hline Earthquake & 2330 & 4.05 & 1.05 & 4.08 & 1.05 & 4.11 & 0.95 \\
\hline Volcano & 2330 & 2.46 & 1.59 & 3.09 & 1.60 & 1.53 & 0.91 \\
\hline All-hazard average & 2330 & 3.02 & 0.81 & 3.20 & 0.76 & 3.41 & 1.10 \\
\hline
\end{tabular}

$M=$ Mean, SD = Standard deviation. Note. Responses provided on a scale from 1-'not at all important' to 5-'very important' for risk perception and on a scale from 1-'very low' to 5-'very high' for the level of worry and the likelihood of occurrence.

On a 1 to 5 scale, with 1 indicating "not at all important" and 5 indicating "very important" risk, the average risk perception is found to be the highest for earthquakes (mean value $M=4.05$ ) and statistically different compared to all the other hazards $(p<0.001)$, followed by wildfires $(M=3.49)$, and floods $(M=3.13)$. All-hazards average was calculated at $M=3.02$, with the rest of natural hazard types ranking lower than this value. Volcano recorded the lowest ranking $(M=2.46)$ out of the nine hazard types (Table 2, Figure 1).

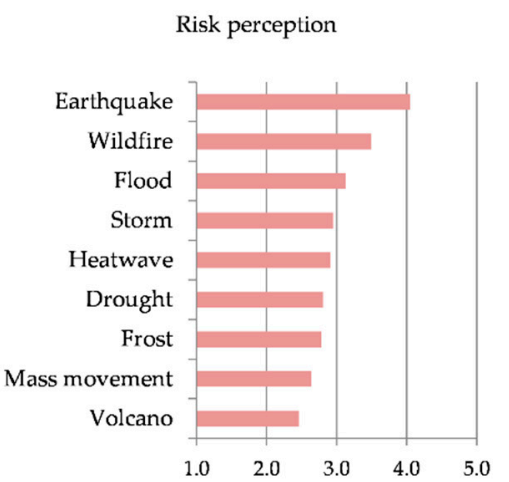

(a)

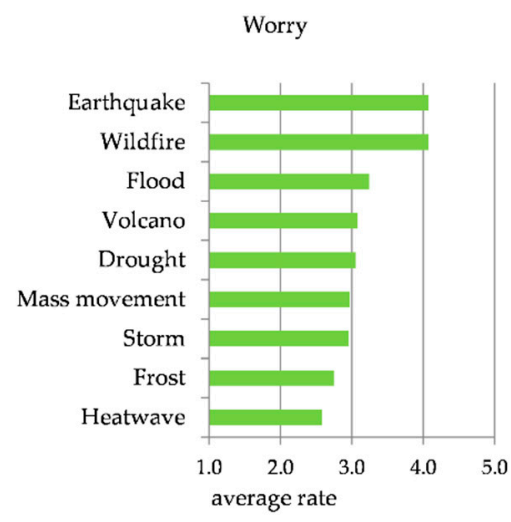

(b)

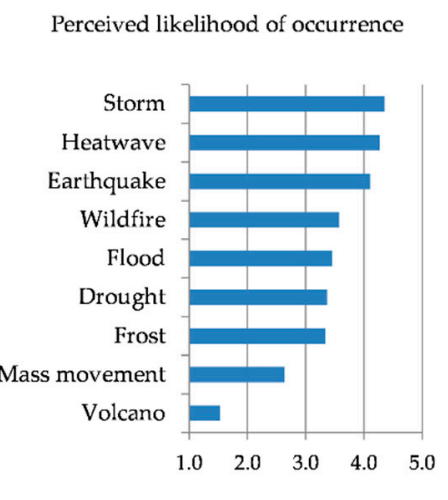

(c)

Figure 1. Average ratings assigned by the participants to the nine types of natural hazards survey, with regard to: (a) Risk perception in terms of importance, (b) feelings of worry they create, (c) perceived likelihood of occurrence.

A similar pattern appears regarding feelings of worry, where the same three hazards (earthquakes, wildfires and floods) stand out from the rest (Table 2, Figure 1). Again, the rest of the hazards score within a narrow range (2.58-3.06) when it comes to feelings of worry they create in the participants, as in the case of risk perception. It is important to note that in both cases, floods seem to be placed somewhere between the group of the first two (earthquakes and wildfires) and the larger group, as they stand out from the latter by a small margin. 
In terms of likelihood, we see roughly three (3) groups of hazards, as far as ranking is concerned (Table 2, Figure 1). The first group, i.e., storms $(M=4.36)$, heatwaves $(M=4.27)$ and earthquakes $(M=4.11)$ are perceived as the most likely (scoring over 4 in the 1-5 scale). The group consisting of frost, wildfires, droughts, and floods comes second, with all hazards scoring close to 3.50 (certainly between 3 and 4). Lastly, mass movements and volcanos, which form the third group, score less than average, with volcanos perceived as the most unlikely of the nine hazards.

Table 3 shows the statistically significant correlations between demographic variables and risk perception for each natural hazard, indicating that apart from gender, all the other correlations are very low and with inconsistent statistical signs, thus not allowing for any generalized conclusions. Nevertheless, as far as gender is concerned, the direction of correlations signifies that males have a lower risk perception independent of the hazard. Additionally, geophysical hazards show weaker correlations $(-0.04$ to -0.07$)$ in comparison to climate-related hazards $(-0.08$ to -0.14$)$.

Table 3. Correlations between demographic variables and risk perception.

\begin{tabular}{|c|c|c|c|c|c|c|}
\hline Hazard Type & Gender $^{1}$ & Age Level $^{1}$ & Income Level $^{1}$ & Ownership $^{1}$ & Education Level $^{1}$ & ${\text { Family Status }(\mathrm{df}(8))^{2}}^{2}$ \\
\hline Storm & -0.14 & 0.05 & & 0.05 & & 39.07 \\
\hline Heatwave & -0.10 & 0.07 & -0.06 & & & 19.63 \\
\hline Frost & -0.14 & & -0.08 & & -0.08 & \\
\hline Drought & -0.08 & & -0.05 & & & \\
\hline Volcano & -0.04 & -0.09 & & -0.06 & & 31.95 \\
\hline
\end{tabular}

Note: Only statistically significant results are provided $(p<0.05)$. The coding of variables is shown in Tables $1, \mathrm{~A} 1$ and A2. ${ }^{1}$ Spearman's rank (rho). ${ }^{2}$ Chi-square test for categorical variables.

Gender also influences the level of worry (Table 4). In particular, males have lower levels of worry. Higher levels of age seem to be clearly associated with higher worry, with the exception of frost and wildfires, for which correlations were statistically insignificant. Higher levels of education and income are also associated with lower worry, although correlations are low and not consistent across all risks.

Table 4. Correlations between demographic variables and worry.

\begin{tabular}{|c|c|c|c|c|c|}
\hline Hazard Type & Gender $^{1}$ & Age Level $^{1}$ & Income Level $^{1}$ & Education Level $^{1}$ & Family Status $(\mathrm{df}=8)^{2}$ \\
\hline Flood & -0.14 & 0.06 & & & 23.54 \\
\hline Storm & -0.12 & 0.12 & & & 30.25 \\
\hline Mass Movement & -0.17 & 0.05 & -0.06 & -0.06 & 25.16 \\
\hline Heatwave & -0.05 & 0.13 & & -0.04 & \\
\hline Frost & -0.21 & & -0.08 & -0.07 & \\
\hline Drought & -0.05 & 0.07 & & -0.06 & 22.79 \\
\hline Wildfire & -0.13 & & -0.05 & & \\
\hline Earthquake & -0.10 & 0.13 & & & 31.90 \\
\hline Volcano & -0.18 & -0.05 & -0.08 & -0.08 & \\
\hline
\end{tabular}

Note: Only statistically significant results are provided $(p<0.05)$. The coding of variables is shown in Table 1. Ownership is not included due to the insignificant correlation results. ${ }^{1}$ Spearman's rank (rho). ${ }^{2}$ Chi-square test for categorical variables.

In line with the previous results, gender was found to associate with the perceived likelihood of hazards' occurrence. Detailed statistical results are presented in Appendix A of this article. Correlations are statistically low ( -0.15 the highest, with earthquake occurrence) and show that males' perception is lower in this case as well (Table A1). Correlations between the perceived likelihood of occurrence and the rest of demographic variables were found, in most cases, insignificant.

\subsection{Disaster Experience}

The Wilcoxon signed rank test revealed a statistically significant increase in risk perception of any natural hazard following an experience of disaster impacts (Table 5). The only exception is volcano 
risk, which is not statistically different between the two groups of participants. The mean level of risk perception for earthquakes increases from the non-experienced group $(M=3.90)$ to the experienced one $(M=4.13)$. Second in both groups ranks the wildfire risk perception, while third is the flood risk perception. The most extensive differences in mean rating $(M)$ between the experienced and the non-experienced respondents appear in wildfires (0.43), floods (0.39) and frost (0.39), whereas earthquakes are in the last place (0.23). The results, in terms of differentiation of perceived volcanic risk due to experience, do not show a statistically significant difference, probably due to the small population sample with relevant experience.

Table 5. Risk perception levels for participants with and without disaster experience.

\begin{tabular}{|c|c|c|c|c|c|c|}
\hline \multirow{2}{*}{ Hazard Type } & \multicolumn{2}{|c|}{ Without Experience } & \multicolumn{2}{|c|}{ With Experience } & \multirow{2}{*}{$p$ Value } & \multirow{2}{*}{ Effect Size } \\
\hline & $M(\mathrm{~N} 1)$ & SE & $M(\mathrm{~N} 2)$ & SE & & \\
\hline \multicolumn{7}{|c|}{ Hydrogeological and climate-related hazards } \\
\hline Flood & $2.93(1166)$ & 0.03 & $3.32(1164)$ & 0.04 & $* * *$ & 0.16 \\
\hline Storm & $2.75(1000)$ & 0.03 & $3.10(1330)$ & 0.03 & $* * *$ & 0.15 \\
\hline Mass movement & $2.55(1409)$ & 0.03 & $2.78(921)$ & 0.04 & $* * *$ & 0.10 \\
\hline Heatwave & $2.76(1002)$ & 0.03 & $3.03(1328)$ & 0.03 & $* * *$ & 0.12 \\
\hline Frost & $2.58(1119)$ & 0.04 & $2.97(1211)$ & 0.03 & $* * *$ & 0.16 \\
\hline Drought & $2.68(1298)$ & 0.03 & $2.96(1032)$ & 0.04 & $* * *$ & 0.12 \\
\hline Wildfire & $3.26(1092)$ & 0.04 & $3.69(1238)$ & 0.04 & $* * *$ & 0.16 \\
\hline \multicolumn{7}{|c|}{ Geophysical hazards } \\
\hline Earthquake & $3.90(821)$ & 0.04 & $4.13(1509)$ & 0.03 & $* * *$ & 0.10 \\
\hline Volcano & $2.47(1588)$ & 0.04 & $2.43(742)$ & 0.06 & + & \\
\hline
\end{tabular}

Note. Responses for risk perception provided on a scale from 1-'very low' to 5-'very high'. $M=$ Mean, SE = Standard error. Significance and effect size calculated using Wilcoxon Signed Rank Test. Effect size calculated as $z / \sqrt{N}$, where $\mathrm{N}$ the total sample observations $(\mathrm{N} 1+\mathrm{N} 2=2330) .{ }^{+} p>0.05,{ }^{*} p<0.05,{ }^{* *} p<0.01{ }^{* * *} p<0.001$.

Furthermore, participants were asked to answer whether the last disaster experience of the specific hazards occurred during "the previous year", "one to five years ago" or "more than five years ago". Kruskal-Wallis test was conducted to examine the differences in risk perception according to the time since the participant's last disaster experience. With respect to the hydro-meteorological hazards, results suggest a statistically significant reduction of average risk perception as the period from the negative experience grows (Table 6). Effects on the perception of storm, heatwave, earthquake, and volcanic risk were found insignificant.

Table 6. Effect of the time since last disaster experience on risk perception for each natural hazard.

\begin{tabular}{cccccc}
\hline $\begin{array}{c}\text { Time Since Last } \\
\text { Experience }\end{array}$ & Flood & $\begin{array}{c}\text { Mass } \\
\text { Movement }\end{array}$ & Frost & Drought & Wildfire \\
\cline { 2 - 6 } & $\boldsymbol{M}(\mathrm{SE})$ & $\boldsymbol{M}$ (SE) & $\boldsymbol{M}$ (SE) & $\boldsymbol{M}$ (SE) & $\boldsymbol{M}$ (SE) \\
\hline last year & $3.55(0.08)$ & $3.19(0.11)$ & $3.11(0.05)$ & $3.13(0.09)$ & $3.86(0.07)$ \\
up to 5 years & $3.44(0.06)$ & $3.04(0.09)$ & $3.02(0.06)$ & $3.15(0.06)$ & $3.81(0.06)$ \\
$>5$ years & $3.16(0.05)$ & $2.65(0.05)$ & $2.62(0.07)$ & $2.74(0.05)$ & $3.55(0.05)$ \\
N & 1164 & 921 & 1211 & 1032 & 1238 \\
Chi square $(p)$ & $20.39\left(^{* * *}\right)$ & $26.70\left(^{* * *}\right)$ & $30.81\left(^{* * *}\right)$ & $30.06\left(^{* * *}\right)$ & $11.88\left(^{* *}\right)$ \\
\hline
\end{tabular}

As expected, prior experience of a natural disaster has a statistically significant and positive correlation with the level of worry for the respective hazard, as well as on the perceived likelihood of occurrence (Figure 2, Table A1). The participants with prior experience demonstrate higher levels of worry and likelihood perception. With regard to likelihood perception, higher differences in mean 
rating $(M)$ appear in most hydrogeological and climate-related hazards $(0.36-0.72)$, in comparison to earthquake hazard (0.28).

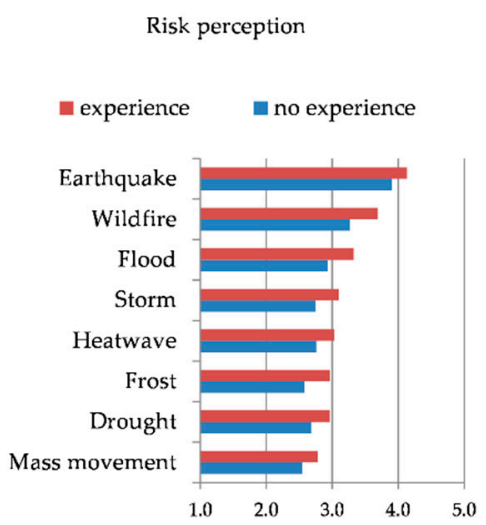

(a)

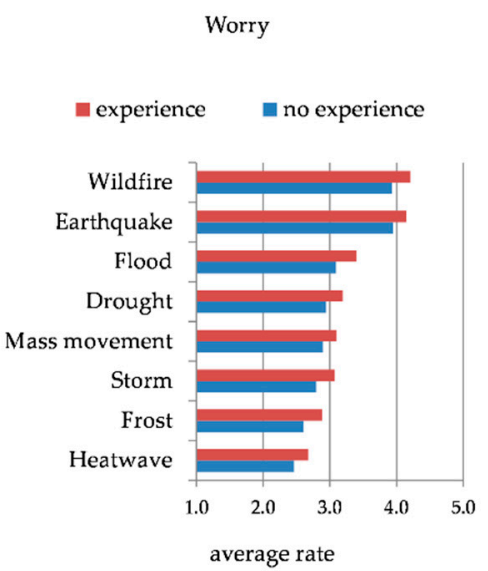

(b)

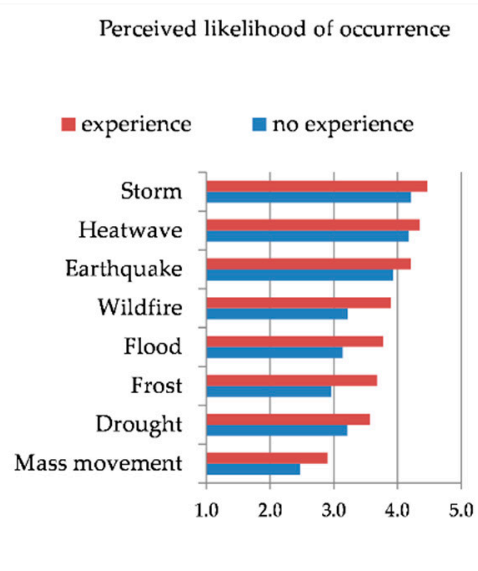

(c)

Figure 2. The effect of previous disaster experience on the average ratings assigned by the participants to the nine types of natural hazards survey, with regard to: (a) Risk perception in terms of importance,

(b) feelings of worry they create, (c) perceived likelihood of occurrence.

\subsection{Awareness and Confidence}

Figure 3 depicts the percentage distribution of the survey participants' answers to three questions about (a) their access to awareness events and informational material, (b) their knowledge of the emergency telephone numbers, and (c) their participation in emergency exercises for other than earthquake hazards. The majority of participants (69\%) stated that they had attended an awareness event or had access to informational material about natural hazards prevention for at least one of the hazards in question, whereas a noteworthy percentage (31\%) did not reply positively on receiving material or attending an event. Additionally, a significant percentage of respondents (27\%) did not provide at least one emergency number correctly. With regard to emergency drills or training exercises (excluding earthquakes that have been taking place in schools for decades), a large percentage $(77 \%)$ stated that they had never participated in one, while only a $21 \%$ replied positively.

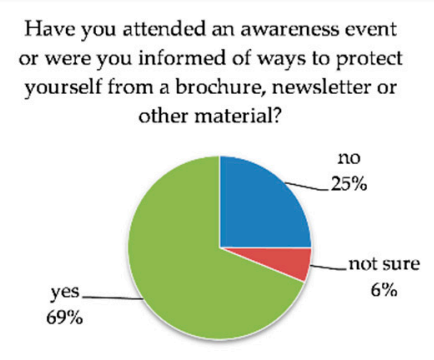

(a)

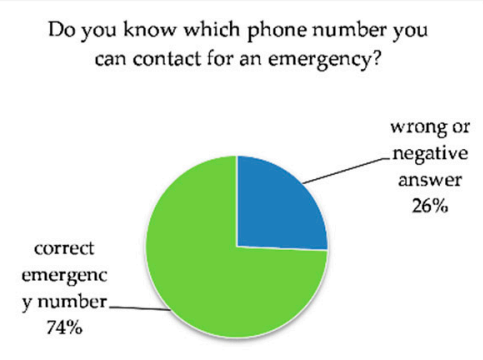

(b)

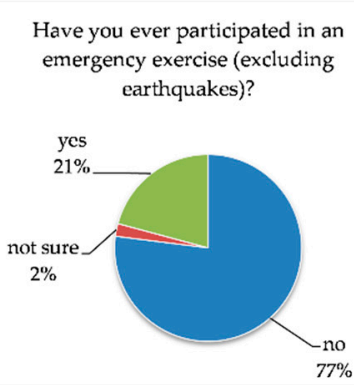

(c)

Figure 3. Survey participants' answers about their access to: (a) Information, (b) emergency numbers, (c) emergency exercise for other than earthquake hazards.

Participants were also asked whether they trust official warnings for hydrogeological and climate-related hazards' risk (Table 7). Average trust is higher for heatwave warnings, followed by trust in storm and frost warnings. 
Table 7. Descriptive data for the variable of individual's trust in warning for climate-related hazards' risk.

\begin{tabular}{cccc}
\hline Hazard Type & Obs & $\boldsymbol{M}$ & SD \\
\hline Flood & 2272 & 2.52 & 1.08 \\
Storm & 2286 & 3.18 & 1.12 \\
Mass movement & 2200 & 2.13 & 0.96 \\
Heatwave & 2275 & 3.44 & 1.09 \\
Frost & 2257 & 3.16 & 1.14 \\
Drought & 2214 & 2.60 & 1.08 \\
Wildfire & 2269 & 2.75 & 1.21 \\
\hline
\end{tabular}

$M=$ Mean, SD = Standard deviation. Note. Responses provided on a scale from 1-'very low' to 5-'very high'.

Higher trust in official early warnings for climate-related hazards is found to be associated with increased levels of the likelihood of occurrence perception (Table A1). Correlations between trust in warnings and likelihood of occurrence are stronger in heatwave and frost hazards (Spearman's rho, 0.14 and 0.13 respectively).

The participants were asked about their overall trust in the local authorities' ability to protect the public from natural hazards. Figure 4 shows the distribution of their answers regarding the levels of trust (from 1-'very low' to 5-'very high'), which is imbalanced, with most answers ranging from 1 to 3. The average rate (2.42) shows a moderate degree of trust in officials.

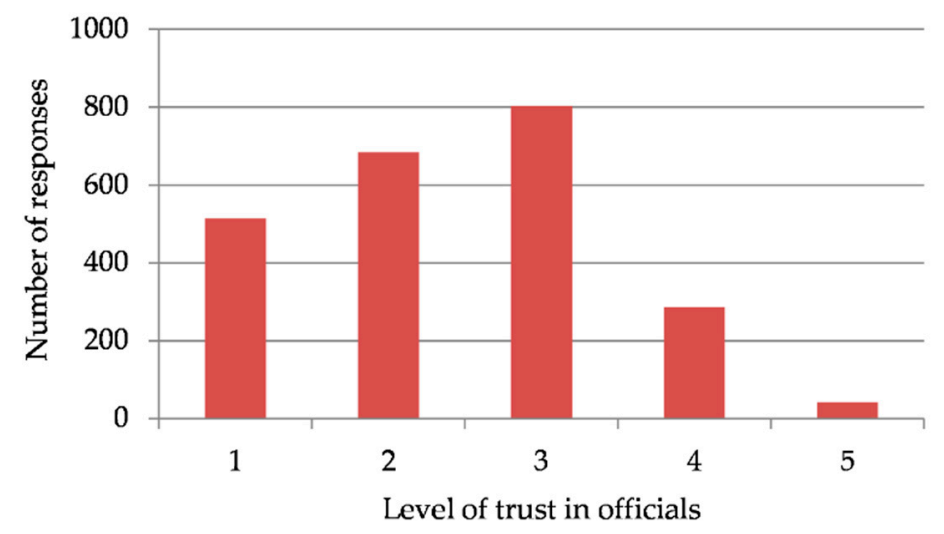

Figure 4. Distribution of survey responses on the 'overall trust in the local authorities' ability to protect the public', on a five-point scale from 1-'very low' to 5-'very high'.

\subsection{Coping Appraisals}

To capture important dimensions of people's coping appraisals, participants were asked:

- To rate the effectiveness of the measures they implemented to cope with each natural hazard (perceived coping capacity).

- To rate their ability to cope with the economic demands of preparing for their protection against natural disasters (cost-response efficacy).

- How well they know what they should do in case of an emergency when a specific natural disaster takes place, that is to rate their emergency response efficacy.

Table 8 provides descriptive data for coping appraisal variables, and Figure 5 illustrates the average ratings per hazard. 
Table 8. Descriptive data for the variables of coping appraisals.

\begin{tabular}{|c|c|c|c|c|c|c|c|c|c|}
\hline \multirow{2}{*}{ Hazard Type } & \multicolumn{3}{|c|}{ Coping Capacity } & \multicolumn{3}{|c|}{ Cost-Response Efficacy } & \multicolumn{3}{|c|}{ Emergency Response Capacity } \\
\hline & Obs & $M$ & SD & Obs & $M$ & SD & Obs & $M$ & SD \\
\hline \multicolumn{10}{|c|}{ Hydrogeological and climate-related hazards } \\
\hline Flood & 1509 & 3.03 & 1.23 & 2330 & 2.37 & 1.09 & 2330 & 3.02 & 1.10 \\
\hline Storm & 1618 & 3.11 & 1.24 & 2330 & 2.59 & 1.15 & 2330 & 3.32 & 1.06 \\
\hline Mass movement & 949 & 2.80 & 1.27 & 2330 & 2.12 & 1.04 & 2330 & 2.46 & 1.12 \\
\hline Heatwave & 1605 & 3.27 & 1.23 & 2330 & 2.80 & 1.18 & 2330 & 3.74 & 0.94 \\
\hline Frost & 1253 & 2.89 & 1.28 & 2330 & 2.61 & 1.21 & 2330 & 3.21 & 1.20 \\
\hline Drought & 1116 & 2.71 & 1.23 & 2330 & 2.43 & 1.12 & 2330 & 2.88 & 1.16 \\
\hline Wildfire & 1326 & 2.83 & 1.28 & 2330 & 2.28 & 1.12 & 2330 & 3.14 & 1.14 \\
\hline \multicolumn{10}{|c|}{ Geophysical hazards } \\
\hline Earthquake & 1524 & 2.70 & 1.23 & 2330 & 2.24 & 1.11 & 2330 & 3.56 & 0.97 \\
\hline Volcano & 504 & 2.67 & 1.46 & 2330 & 1.79 & 1.03 & 2330 & 1.83 & 1.12 \\
\hline
\end{tabular}

$M=$ Mean, $\mathrm{SD}=$ Standard deviation. Note. Responses provided on a scale from 1-'very low' to 5-'very high'.

Coping capacity

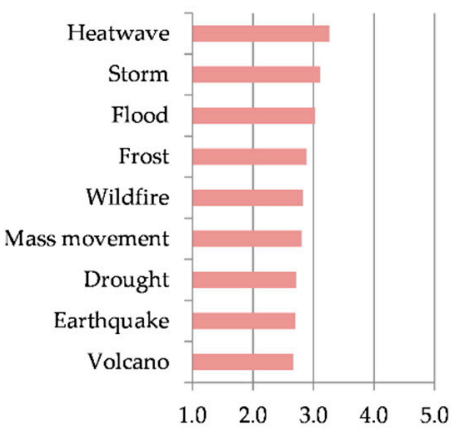

(a)

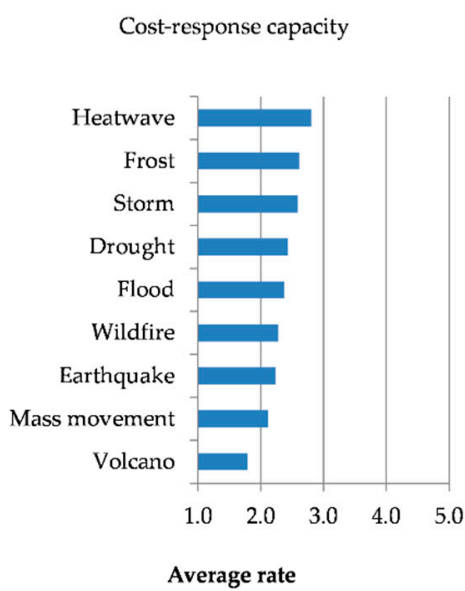

(b)

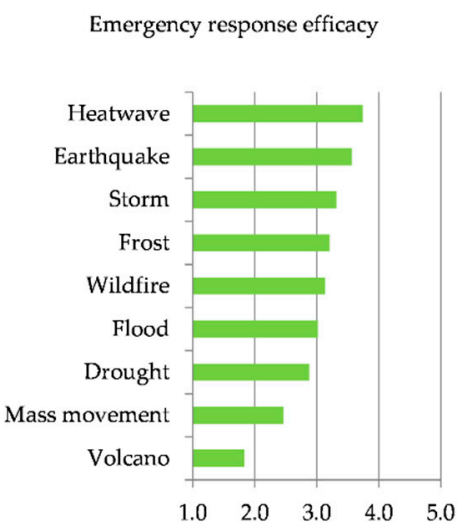

(c)

Figure 5. Average ratings assigned by the participants to the nine types of natural hazards survey, with regard to: (a) Coping capacity, (b) cost-response capacity, (c) emergency response efficacy.

Geophysical hazards tend to score lower ratings, in both coping and cost-response capacity. Given that earthquakes rank first in risk perception and worry, the low coping and cost-response capacity may be affected by the perceived importance of the risk. With regard to emergency response efficacy, the respondents' answers place heatwaves, earthquake, and storms in the first three positions, as they do in perceived likelihood rankings. Similarly, they place mass movement and volcano in the last two positions, exactly as they do in perceived likelihood of occurrence. Thus, the pattern appearing here (perceived emergency response efficacy) is similar to the one appearing in perceived likelihood (Figure 6), in terms of grouping hazards into three groups of ranking.

Statistical results (Table A1) revealed significant and positive correlations between the awareness-related variables and coping appraisals, particularly the public's emergency response efficacy. Figure 7 shows that across all hazard types mean emergency response efficacy rating is systematically higher for the participants that gave positive answers in all three awareness-related questions, in comparison with the ones that gave negative and "not sure" responses.

Disaster experience was also found to associate in particular with the emergency response efficacy (Table A1). The results revealed a statistically significant increase in emergency-response efficacy following a negative experience of any hazard. The effect of experience is higher in hydro-meteorological hazards (rho, 0.13-0.20) compared to geophysical ones (rho, 0.05-0.12). 


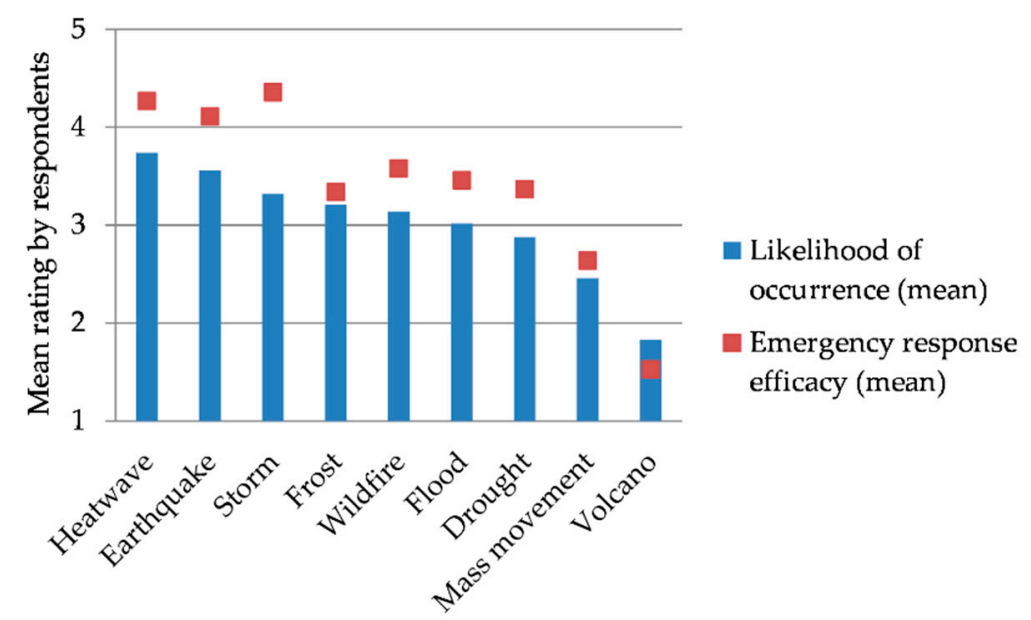

Figure 6. Comparison of mean rating (on a 1-5 scale) of perceived emergency-response efficacy and likelihood of occurrence, across all hazard types.

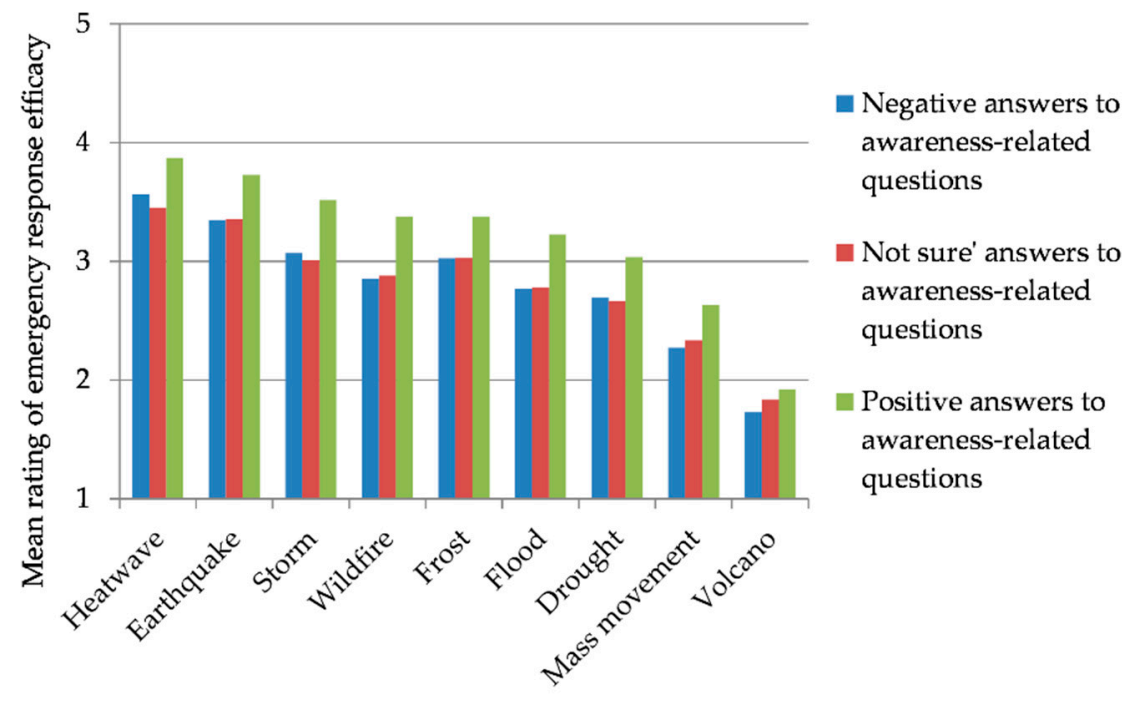

Figure 7. Comparison of mean rating of emergency response efficacy between positive, negative and "not sure" answers to the three awareness-related survey questions of Figure 3, across all hazard types.

Feelings of trust were also found to associate with coping appraisals (Table A1). Both trust in officials and trust in scientific warnings were positively correlated with all three coping appraisal variables across all hazards. Trust in officials exhibited stronger correlation with cost-response capacity (rho from 0.17 with volcano to 0.23 with flood hazard), while trust in scientific warnings correlated with emergency response efficacy (rho from 0.21 for flood to 0.32 for frost hazard).

Among the demographic attributes, gender was found to be correlated with all three coping appraisal variables across the climate-related hazards. Correlations in the case of geophysical hazards were either very low or insignificant. Specifically, males were found to rate their coping potential higher. Additionally, high positive correlations were found between the level of education or income and cost-response capacity, across all hazard types. Conversely, education, income, as well as home ownership, were found to associate neither with coping capacity nor with emergency response efficacy. Correlations of coping appraisals with age were low or insignificant across hazards.

\subsection{Preparedness against Natural Hazards}

In order to record the level of preparedness of the public against natural hazards, participants were asked to choose the measures they implemented from a predefined list. The share of participants 
who have not taken any measure is estimated at $22 \%$. Among those who have implemented at least one precautionary measure $(78 \%)$, the percentage of respondents who reported more than one measure is $85 \%$. Figure 8 shows the frequency of adoption of prevention measures at property.

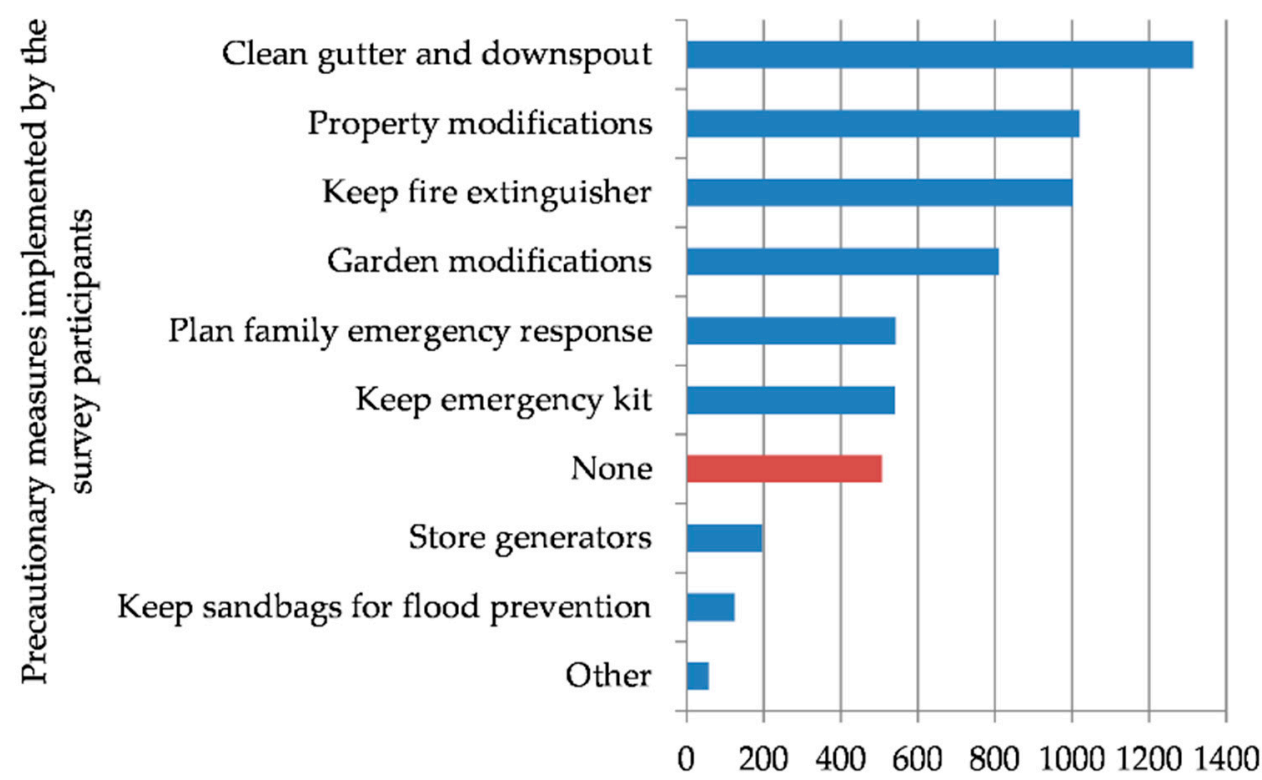

Number of responses (multiple-choice)

Figure 8. Frequency of adoption of prevention measures at property.

In order to measure respondents' preparedness, we developed a set of nine dichotomous items, each one measuring the adoption of the specified precautionary measure. The generated preparedness variable was constructed from the aggregation of the dichotomous items from this set (Kuder-Richardson formula 20 test of internal reliability, KR-20 $=0.60$ ). The ordinal preparedness variable takes values from $0=$ 'no measures implemented' to $9=$ ' 9 measures implemented'. In this case, the mean was found to be $M=2.41(N=2330, \mathrm{SD}=1.78)$.

Preparedness was found to have a significant and positive correlation with disaster experience (Table A2, Figure 9a). Depending on the natural hazard, Spearman's correlation coefficients, rho, vary from 0.15 (with earthquake experience) to 0.21 (with wildfire experience). In what concerns the correlation of preparedness with feelings of worry among the natural hazards under examination, its strength is highest for the hydrogeological hazards, lower for the climatic ones, and insignificant for the geophysical ones (Figure 9a). Consequently, the higher preparedness levels are mostly associated with the higher worry for the hydrological hazards. Risk perception, on the other hand, demonstrates a significantly lower association with preparedness, a pattern seen also in Diakakis et al. [54]. Specifically, depending on the natural hazard, Spearman's rho varies from 0.06 (with frost risk perception) to 0.11 (with storm risk perception), while correlations of preparedness with earthquake and heatwave risk perceptions are insignificant $(p>0.05)$.

Among the statistically significant correlations involving preparedness (Table A2), the strongest ones were found between preparedness and coping appraisals, especially the emergency response efficacy (Figure 9b). Correlations are quite stronger in flood, storm, and wildfire hazards (rho, 0.27-0.30), showing that people with high confidence in their ability to respond to an emergency have taken in practice more measures to cope with these emergency situations. 


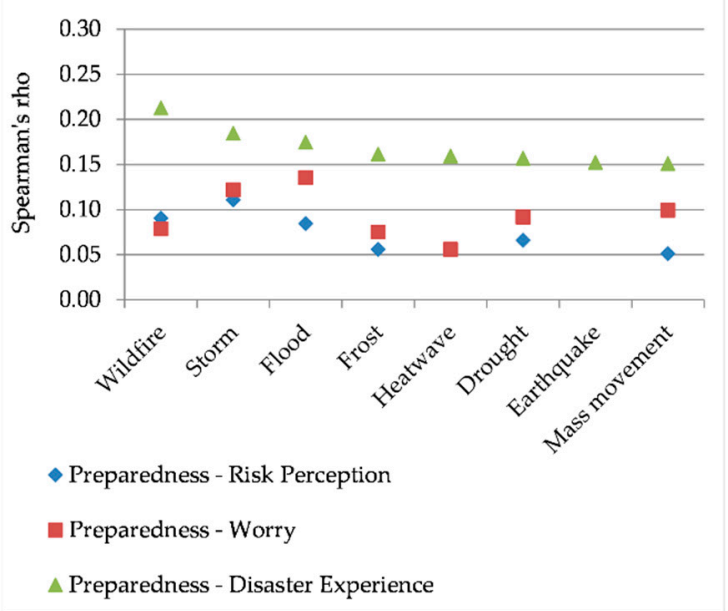

(a)

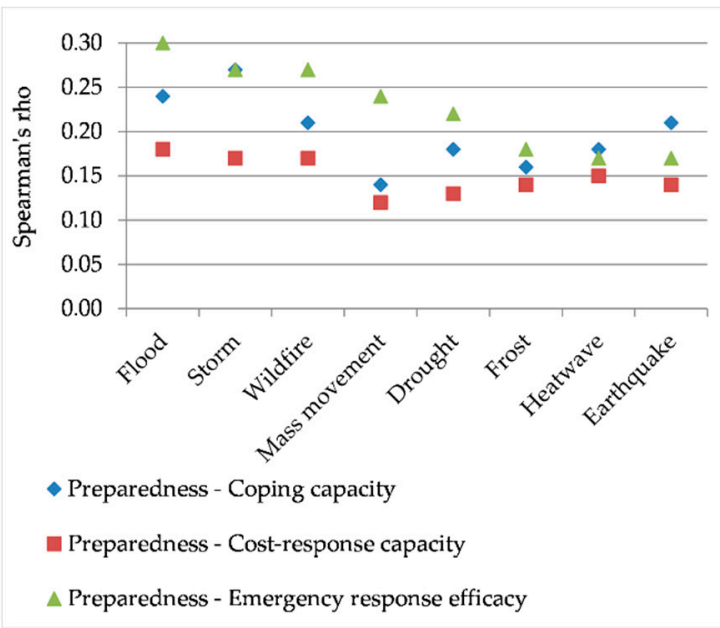

(b)

Figure 9. Correlation strength (Spearman's rho) between preparedness and: (a) Risk perception, feelings of worry, and disaster experience, (b) coping appraisals, across all hazard types (only significant results are depicted, $p<0.05)$.

Participants were then asked whether they had purchased insurance coverage for natural disasters. Figure 10 illustrates the percentage distribution of the responses. The majority of the respondents do not have any insurance coverage $(64 \%)$. In what concerns the participants with insurance coverage (28\%), half of them were obliged in the context of a bank loan. Excluding the uncertain responses ('not sure'), we also constructed a binary variable for insurance coverage $(0=$ 'no', $1=$ 'yes' and 'yes due to loan requirement'). Only $14 \%$ purchased insurance willingly.

\section{Do you have any insurance coverage for natural disaster on your property?}

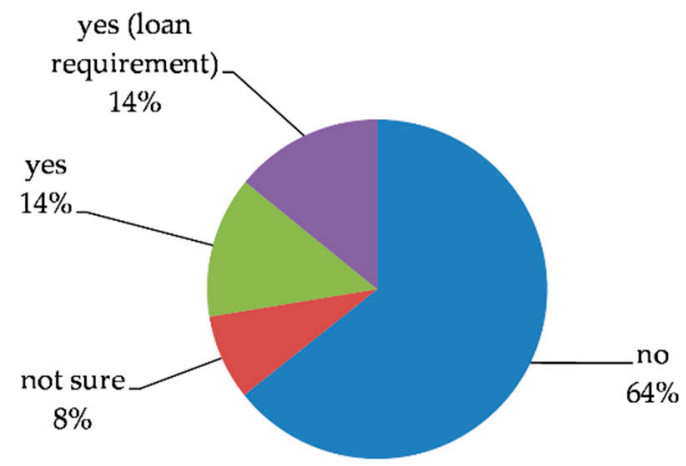

Figure 10. Distribution of answers with regard to the purchase of insurance.

According to the statistical results presented in Table A2 of Appendix A, the purchase of insurance coverage is consistently correlated with cost-response capacity across all hazards, while correlations with coping capacity, emergency response capacity, and threat perceptions are either low or insignificant. Overall demographics were found to correlate with precautionary behaviors (Table A2). More specifically, home ownership, higher family income, and higher age level are all associated with increased preparedness and the purchase of insurance coverage. Gender and education level demonstrate a weak association with precautionary behaviors. 


\subsection{Cognitive Map of Relationships among the Set of Variables for Climate-Related Hazards}

Figure 11 illustrates the statistically significant correlations found between the survey variables across the hydrogeological and climate-related hazards. The structure is based on theoretical models of protection motivation processes in psychology and their implementation in empirical research on flood-risk precautionary behaviors [40,44,63]. The exact correlation results (Spearman's rho coefficients) can be found in Tables A1 and A2 in Appendix A.

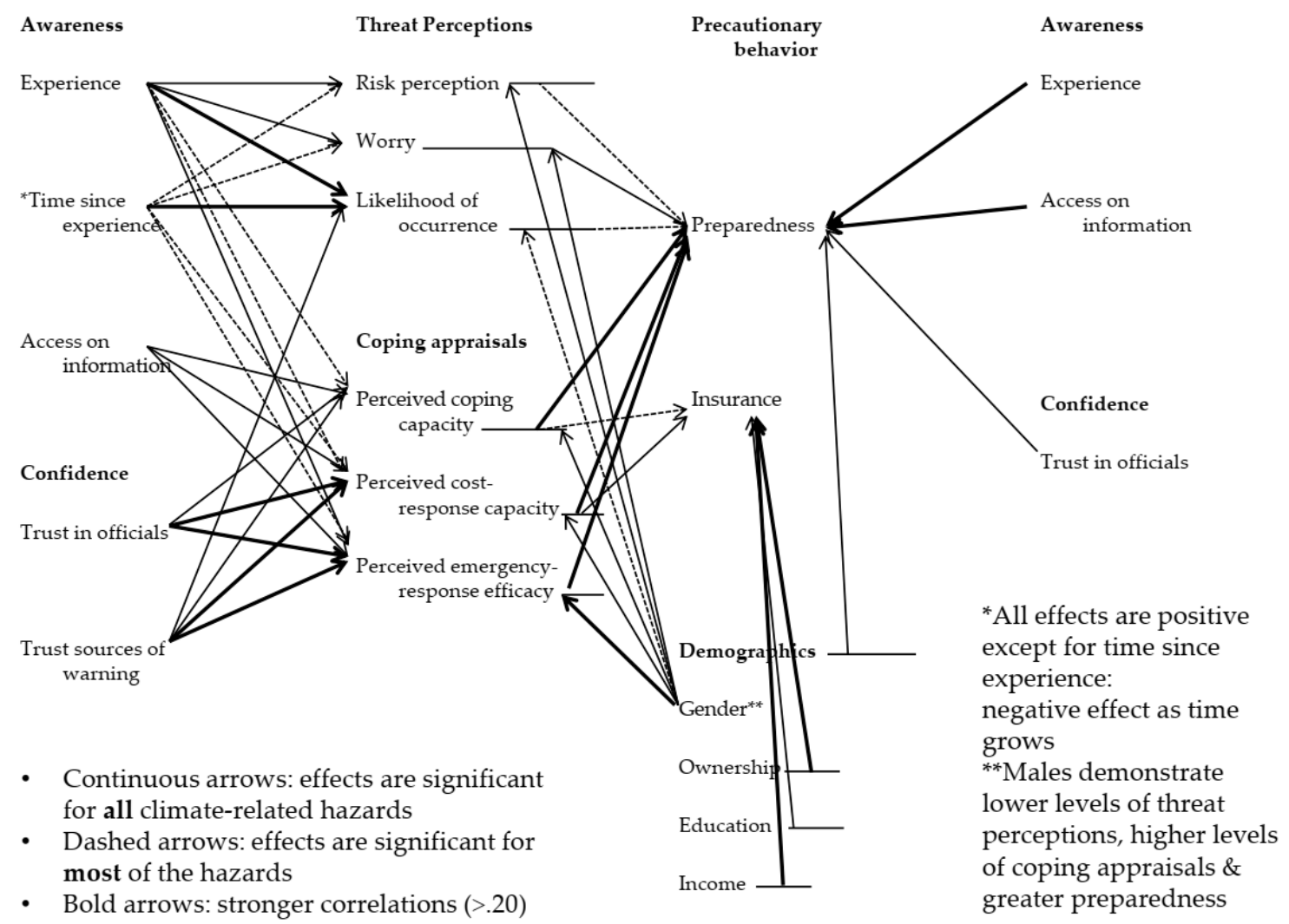

Figure 11. Cognitive map of the statistically significant correlations found between the survey variables related to the hydrogeological and other climate-related hazards.

Our results provide evidence of the central role, in terms of a significant positive effect, that disaster experience and awareness have on threat perceptions and coping appraisals, which, in turn, are shown to affect individual preparedness (shown also by Poussin et al. [44] and Papagiannaki et al. [40], which focus on flood risk perception).

A difference found compared to previous studies on flood-risk preparedness is the absence of correlation between trust in the officials and risk perception or worry, for any of the hazards, as well as a positive correlation between trust and preparedness. Specifically, Terpstra [64] and Papagiannaki et al. [40] found that trust in authorities, with regard to the risk mitigation strategies they adopt at the local level, had a significant negative effect on risk perception, worry, and also on preparedness for flood hazard. In the present study, however, trust is found to positively correlate with coping appraisals, while this relationship was not examined in previous studies.

\section{Discussion}

Given the limited understanding of risk perception in the region and its criticality in risk mitigation, this work explores laymen's perception and views on hydrogeological and other climate-related hazards against geophysical hazards in a characteristic case of multi-hazard environment. The study provides 
basic insights into how different types of natural hazards compare with each other in terms of risk perception, feelings of worry, and coping appraisal. In addition, it identifies patterns and links between perceptions, demographics, and behavioral variables, in an effort to shed light on pathways to enhance citizens' protective behavior. These links are expected to be crucial in the coming years, given the projected increase in climate-related catastrophic events, but also given the established criticality of protective behavior that leads to private adaptation measures, which, in turn, have been found to have an important effect on flood consequences [65].

\subsection{Threat Perceptions}

Overall, earthquakes come first, in both feelings of worry and importance of risk, and score quite high in perceived likelihood. They are followed by wildfires and floods in all three fields. Threat perception results are in agreement with previous findings in Greece [54] in terms of ranking of the first three most important hazards in the country (earthquakes, wildfires, and floods). The ranking assigned could be influenced by several factors. Firstly, the region has experienced catastrophic earthquake events with devastating damages and numerous fatalities [66-69]. The Eastern part of the Mediterranean has been found to record the highest earthquake risk in Europe [70] and the results of the current survey show that a large percentage of people have relevant experiences. Previous devastation from earthquakes is accompanied by perception biases, as highlighted by Slovic et al. [71] and Slovic [72]. Their findings suggest that people tend to have an increased fear towards phenomena or hazards that seem uncontrollable, rare/unfamiliar, or catastrophic when they occur, which is the case for major earthquakes in the region. Catastrophic wildfires have most probably affected respondents' opinion given also their numerous victims $[10,73]$. The tragic death toll of wildfires was accompanied by damages in infrastructure and the environment and has caused public outrage [74].

The ranking deriving from risk perception does not reflect necessarily objective risk impact indicators. For instance, fatalities caused by floods are much higher than those caused by wildfires in the region $[9,10,73,75,76]$. Moreover, flood is the most common climate-related phenomenon provoking damages in the region $[77,78]$. Flood is also perceived as less likely to occur than wildfire, heatwave, storm and even earthquake, while actually the phenomenon occurs more often but mostly as low or zero-impact event. Finally, worry for flood hazard is on average quite lower than for earthquake and wildfire hazards. Our findings suggest that laymen underestimate certain hazard risks, which may inhibit appropriate preparation and allow the disturbance of lives and properties.

In general, worry for a hazard is systematically found higher when compared with the same hazard's "risk perception". Thus, the emotional aspect of perception related to hazards' adverse effects is, in general, more pronounced. However, the participants rated higher the likelihood of a hazard to occur in comparison to the feelings of worry for the respective hazard. The only exceptions are the wildfire and mass movement, for which worry is higher than the likelihood perception. This may be affected by the fact that many respondents live in cities and, therefore, they rarely see wildfires and mass movements.

\section{Factors Influencing, or Are Influenced by Threat Perceptions}

Previous experience, as described in the literature, has been found to play a role in shaping perceptions of all hazards' risk. In particular, direct experience has been proven to influence individuals' risk perception and preparedness against floods [30] or earthquakes [79]. Our findings show that experience affects all threat perceptions and particularly the likelihood of occurrence. Phenomena such as volcanic eruptions and frost that have not caused serious damages in the recent decades in the country have systematically lower risk perception ratings but are still correlated with previous experience. It is interesting to note that hydro hazards show more extensive difference between experienced and non-experienced individuals, with a range of $0.23-0.43$ (average 0.33 ) in comparison to geophysical hazards (earthquakes 0.23 ). Although specific data are not available, this is probably attributed to the particularly high values of risk perception even for people who have not experienced 
earthquakes, probably based on information, visuals and/or experiences received indirectly. This leads to a value of 3.90 (close to 4 "important"), which, compared to the average of 2.78 of climate-related hazards (of which wildfires are ranked above 3 ), is considered to be particularly high.

Although experience has proven to stimulate threat perceptions and to motivate preparedness (Figure 11), it may fade out over time. Our results show that the older the experience, the lower the worry, the risk perception and especially the perceived likelihood of occurrence for most of the hydrogeological and climate-related hazards, including floods, mass movements, wildfires, and drought. Storms and heatwaves happening every year did not show significant differences. Interestingly, earthquake threat perceptions were not influenced by the time elapsed since the most recent experience, which indicates a strong imprint of these events on people's mind.

Correlations with gender are consistent across all hazard types and even though weak, there is a higher discrepancy between males and females in climate-related hazards in comparison to geophysical ones, particularly with regard to risk perception. Results indicating that males perceive lower levels of risk compared to females have been broadly highlighted in recent studies $[31,40,80]$. It is very interesting though to note that among the examined hazards, prioritization of the importance of risk is almost identical for both genders. The same pattern is identified for the level of worry and the likelihood of occurrence. This consistent prioritization between genders is important when it comes to risk awareness-raising policies as it indicates that females and males perceive the level of threat differently. Indeed, Figure 12 shows the average risk perceptions by gender for respondents with experience, with hazards sorted in a descending order based on female perception. Sorting by hazard is practically the same in males, with the only exception being the place of heatwave.

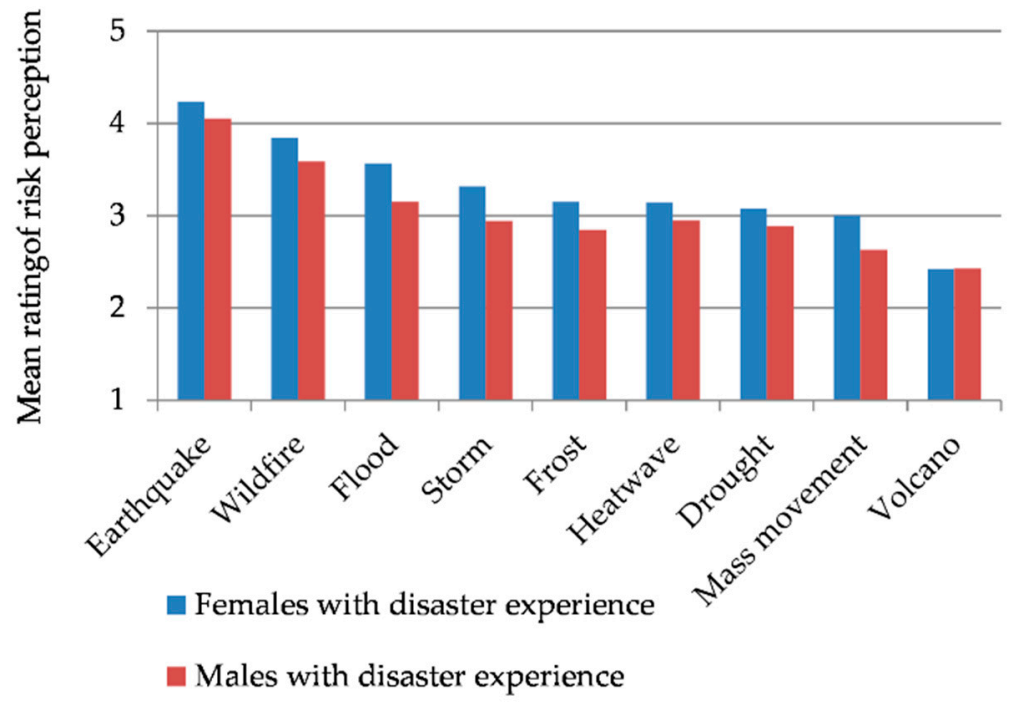

Figure 12. Average risk perception by gender and hazard, among respondents with disaster experience.

In line with current empirical findings $[64,80]$, hydrogeological and climate-related hazards threat perceptions are found to motivate preparedness, in terms of the amount of precautionary measures taken. Further, results of the present work indicate that both cognitive and emotional components of risk perception are significant predictors of individuals' precautionary behavior. This finding is consistent with the theoretical frameworks and empirical findings about the complementary role that basic processes in risk perception, namely 'risk-as-analysis' and 'risk-as-feeling', play in decisions regarding how to deal with risks $[81,82]$.

On the other hand, insurance purchase is not affected by any of the variables, including threat perception. A very weak correlation was only found between storm risk perception or worry and insurance purchase. Similarly, Thieken et al. [83] found that there was no statistically significant 
relationship between the estimated probability of being affected by future floods and the insurance coverage of private households in Germany.

Interestingly, preparedness level was not found to be related to earthquake threat perceptions, which is in line with recent findings showing insignificant effect of dread feelings on the perceived level of earthquake preparedness in the Los Angeles County [50]. Older empirical findings also suggest that neither the anticipation of earthquake-related damage [84] nor the earthquake risk perception [85] is associated with the adoption of hazard adjustments. This is probably attributed to a belief among citizens that their actions could not improve their level of protection against this catastrophic threat. Secondly, it could be partly attributed to the level of investment needed to improve building's structural integrity, which would surpass the cost of any measures targeting prevention from other hazard types.

\subsection{Coping Appraisals}

The ranking of hazards based on coping capacity shows a reasonable appraisal of the effectiveness of measures taken. Current practices for protection against heatwaves, storms, and frost, for example, are quite standardized and proven effective measures (e.g., air-conditions, building insulation). Flood protection is also partly standardized, although its effectiveness depends largely on vulnerability due to local topographic and morphological features. The lower ranking of wildfires, mass movements, drought, and geophysical hazards is thus consistent with the higher difficulty in identifying and implementing effective measures. Similarly, ranking deriving from cost-response appraisal shows a reasonable appreciation of the expenses needed for protection against each hazard. Preventive measures for heatwaves, storms, and frost cost relatively less than interventions required to cope with flood or earthquake risk. In terms of emergency coping appraisal, it is worth noting the high score for earthquakes. This probably reflects the systematic education of earthquake emergency response in schools and in many public and private companies.

Comparison between ranking of hazards based on threat perceptions and coping appraisals indicates that people, in general, people tend to believe they can cope more with hazards they worry less about, i.e., heatwaves, storms, and frost. In what concerns the emergency response efficacy, it was rated higher for the hazards that are assumed more likely to occur. Thus, people probably acknowledge it is either easier or more important to increase their emergency response efficacy for hazards that are more likely to occur, such as heatwaves, storms, but also earthquakes.

\section{Factors that Influence or Are Influenced by Coping Appraisals}

According to our results, prior experience has a particular impact on the assessment of the citizen's ability to respond to a future climate-related emergency situation, which, in turn, influences preparedness (Figure 8). Prior experience is also found to have a positive effect directly on preparedness across all hazards, in line with previous studies [86].

Access to information is found to influence the capacities to cope with natural hazards rather than the perception of threat. Risk communication can increase coping appraisals, which, in turn, influence preparedness, including the purchase of insurance coverage. As expected, due to its costly nature, people with insurance are associated with higher ability to meet the cost. Interestingly, the cost-response appraisal was found to be the only variable affecting the option of insurance coverage. Moreover, as shown in Figure 11, evidence is provided about the association of private insurance coverage with purely economic criteria (perceived cost-response efficacy, income, education, and ownership).

Overall, variables related to awareness (experience, access to information, participation in emergency exercises) show a stronger correlation with the emergency response efficacy (Table A1) and this applies to all types of hazards. Hence, the benefits of specialized information include increasing citizens' confidence in their ability to cope with risk. What is also important is that this information uptake is found to lead to higher preparedness levels, either directly or through the increase of coping appraisals (Table A2, Figure 11). 
Finally, our results show that among the factors affecting coping appraisals for climate-related hazards is the level of trust in the warnings provided by meteorological forecasters, as well as the trust in the officials to protect them. Both these confidence-related attitudes seem to promote a positive attitude towards precautionary behavior.

\section{Conclusions}

The present work aimed to shed light to the perceptual and behavioral attitudes of people against hydrogeological and other climate-related hazards in the multi-hazard Mediterranean environment of Greece. Based on the hypothesis that threat perceptions vary between natural hazards, especially when these coexist in the area, we used the geophysical risks as a reference point for a better evaluation of the results. In addition, based on established behavioral models, we developed a cognitive map of the links of factors that affect, are influenced by, and complement the perceptions of climate-related hazards. The main conclusions are the following:

- People consider earthquake the most dangerous and worrisome hazard, followed by wildfires and floods. Overall, hydrogeological hazards cause less concern, although phenomena such as floods occur more frequently and cause in total more damage. Paradoxically, even though earthquake risk is considered so high, preparedness is not proportional to threat perceptions. Conversely, climate-related and mostly hydrogeological threat perceptions are found to influence preparedness levels.

- Threat perceptions are strongly affected by disaster experiences across all hazards, although their influence tends to decrease as time passes from last experience, particularly for climate-related hazards. Climate-related threat perceptions are more influenced by disaster experience compared to earthquakes.

- Males are more restrained as regards negative emotions and provide lower risk perception ratings, particularly in what concerns hydrogeological hazards. This is associated with higher mortality of males in some climate-related hazards (i.e., wildfires and floods), as males prove to be more vulnerable [9]. Nevertheless, both genders rate their perceptions among hazards with the same order.

- Coping appraisals are influenced at a similar degree by access to information and trust in the officials across all the examined natural hazards.

- Coping appraisals influence at a similar degree the levels of preparedness across all hazards.

- Private insurance coverage is purely a matter of economic criteria.

Overall, the study shows that the society is significantly concerned with certain climate-related hazards, but in a multi-hazard environment, where geophysical hazards have a strong presence, earthquakes clearly surpass other types in all metrics. This perception regime has the potential to influence public debate and policy priorities, eventually affecting what is done in terms of prevention of each type of hazard. Thus, in these types of multi-hazard environments, geophysical risks may consume more of the resources available for natural hazards protection in different ways (e.g., funding-wise, personnel-wise, etc.), and therefore, could lead to deficiencies in climate-related hazards management and adaptation of relevant measures. This is an important conclusion that has not been acknowledged in previous work. Given the lack of comparative studies in the literature, especially in multi-hazard environments, the results cover a research gap on risk perception of hydrological and climate-related hazard. On the other hand, some of the organizational structures developed to deal with geophysical risks may provide the foundations to enhance prevention when it comes to other hazard types. Further research in the region should study, following the same approach, the views of civil protection officials and risk professionals on multiple hazards, to examine whether this group of people shares the perceptions and priorities identified in this study (as relevant literature indicates [87], that is often the case. If indeed this is the case, then efforts to enhance education and training in both laymen and 
experts should be focused on improving possible shortcomings at the level of risk management of climate-related hazards.

The results of the present study have practical implications in planning interventions to inform citizens about natural hazards and risks. These interventions should aim at influencing threat perceptions and coping appraisals as important motivators of individual precautionary behavior. For example, public awareness campaigns could include experiential techniques to stimulate risk perception and persuade the recipient about the effectiveness of precautionary behavior. Profiting from prior disaster experience to achieve stronger risk communication and motivate precautionary behavior has been highlighted in the literature $[47,88]$. In addition, the basic insights on different risk perceptions provided in this study, can guide further targeted investigations of precautionary behavior and how it can be influenced. The natural climate-related risks should be highlighted as significant threats, especially given the adverse climate change predictions for the region with regard to flooding, mass movement phenomena and forest fires [12-14]. This could strengthen the community's views and, in turn, could even influence positively the public agenda regarding prevention and protection from such risks.

Results also highlight the important role of a focused and coordinated effort by authorities and scientists to inform citizens and build a trustful relationship in motivating individual preparedness. This effort can capitalize on the basic elements of current risk perception found in this study, provided that officials and policy makers will be appropriately trained and informed. Indeed, access to information, trust in official risk mitigation strategies and trust in scientific warnings were shown to provoke higher coping appraisals and preparedness levels. The small percentage of insurance cover, combined with its correlation with factors related to purely economic criteria, highlight the need for targeted incentives to stimulate the purchase of insurance against natural disasters.

The practical implications arising from this study may apply to other countries in the region and in other multi-hazard environments as well, such as Japan or the western part of the Americas (especially regions with similar climate, such as California). The basic elements of risk perception in multi-hazard environment and their influence on behavior can provide important insights to shape educational and training to the general public and to specific social groups (e.g., students), aiming to enhance protective behaviors against hydrogeological and climate-related hazards.

Supplementary Materials: The following are available online at http:/www.mdpi.com/2073-4441/11/9/1770/s1; The on-line web-based survey questionnaire on multi-hazard (climate-related and geophysical hazards) risk perception, translated from Greek to English.

Author Contributions: Conceptualization, K.P., M.D., V.K., K.L., E.A.; Compilation of the questionnaire, K.P., M.D., V.K., K.L., E.A.; Data collection, K.P., V.K., K.L.; Data analysis, K.P., M.D.; Software K.P., writing-original draft preparation, K.P., M.D., V.K.; Writing, review and editing, K.P., M.D., E.A.

Funding: This research received no external funding.

Conflicts of Interest: The authors declare no conflict of interest.

\section{Appendix A}


Table A1. Correlations (Spearman's rho coefficient) between awareness/confidence/demographic variables and threat perceptions/coping appraisals, per hazard.

\begin{tabular}{|c|c|c|c|c|c|c|c|c|c|c|}
\hline \multirow[t]{2}{*}{ Hazard } & \multicolumn{2}{|c|}{ Hydrogeological } & \multirow[b]{2}{*}{$\begin{array}{c}\text { Mass } \\
\text { Movements }\end{array}$} & \multicolumn{2}{|c|}{ Climate-Related } & \multirow[b]{2}{*}{ Wildfire } & \multirow[b]{2}{*}{ Drought } & \multicolumn{2}{|c|}{ Geophysical } & \\
\hline & Flood & Storm & & Heat & Frost & & & Earthquake & Volcano & \\
\hline $\begin{array}{c}\text { Variable (Specifications) } \\
\text { AWARENESS }\end{array}$ & & & & & & & & & & Variable \\
\hline Disaster Experience $^{1}$ & & & & & & & & & & THREAT PERCEPTIONS \\
\hline \multirow{6}{*}{$\begin{array}{c}(\text { Binary } 0=\text { no experience } 1= \\
\text { experience })\end{array}$} & 0.16 & 0.15 & 0.10 & 0.12 & 0.16 & 0.16 & 0.12 & 0.10 & n.s. & Risk perception \\
\hline & 0.14 & 0.12 & 0.08 & 0.10 & 0.12 & 0.13 & 0.10 & 0.09 & 0.05 & Worry \\
\hline & 0.27 & 0.15 & 0.17 & 0.09 & 0.28 & 0.25 & 0.16 & 0.14 & 0.09 & $\begin{array}{l}\text { Likelihood of occurrence } \\
\text { COPING APPRAISALS }\end{array}$ \\
\hline & n.s. & 0.07 & n.s. & 0.05 & 0.06 & n.s. & n.s. & n.s. & n.s. & Coping capacity \\
\hline & 0.05 & 0.06 & n.s. & 0.04 & 0.10 & 0.08 & n.s. & n.s. & 0.05 & Cost-response capacity \\
\hline & 0.15 & 0.18 & 0.11 & 0.10 & 0.20 & 0.19 & 0.13 & 0.12 & 0.05 & Emergency response efficacy \\
\hline Time since last experience ${ }^{1}$ & & & & & & & & & & THREAT PERCEPTIONS \\
\hline \multirow{6}{*}{$\begin{array}{c}\text { (Ordinal } 1=\text { last year } 2=\text { up to } 5 \\
\text { years } 3=>5 \text { years) }\end{array}$} & -0.14 & n.s. & -0.18 & n.s. & -0.15 & -0.10 & -0.16 & n.s. & n.s. & Risk perception \\
\hline & -0.12 & n.s. & -0.08 & n.s. & n.s. & n.s. & -0.15 & 0.07 & n.s. & Worry \\
\hline & -0.28 & -0.20 & -0.31 & -0.21 & -0.37 & -0.20 & -0.37 & -0.08 & n.s. & Likelihood of occurrence \\
\hline & n.s. & n.s. & 0.11 & n.s. & -0.13 & n.s. & n.s. & n.s. & 0.17 & $\begin{array}{l}\text { Coping capacity } \\
\text { Cofs }\end{array}$ \\
\hline & n.s. & -0.10 & n.s. & n.s. & -0.08 & n.s. & n.s. & -0.07 & n.s. & Cost-response capacity \\
\hline & -0.08 & n.s. & -0.13 & n.s. & -0.24 & n.s. & -0.15 & -0.07 & n.s. & Emergency response efficacy \\
\hline Access to information ${ }^{2}$ & & & & & & & & & & THREAT PERCEPTIONS \\
\hline \multirow{6}{*}{$\begin{array}{l}\text { (Binary ('not sure' excluded) from } \\
\quad \text { correlation) } 0=\text { no } 1=\text { yes) }\end{array}$} & n.s. & n.s. & n.s. & n.s. & n.s. & 0.04 & 0.04 & n.s. & n.s. & Risk perception \\
\hline & n.s. & n.s. & n.s. & n.s. & n.s. & 0.08 & n.s. & 0.06 & n.s. & Worry \\
\hline & n.s. & n.s. & 0.06 & 0.04 & n.s. & n.s. & n.s. & 0.06 & n.s. & Likelihood of occurrence \\
\hline & 0.11 & 0.13 & 0.13 & 0.06 & 0.10 & 0.14 & 0.08 & 0.08 & 0.16 & $\begin{array}{l}\text { Coping capacity } \\
\text { Cors }\end{array}$ \\
\hline & 0.14 & 0.16 & 0.15 & 0.15 & 0.15 & 0.15 & 0.12 & 0.13 & 0.04 & Cost-response capacity \\
\hline & 0.19 & 0.19 & 0.21 & 0.16 & 0.13 & 0.20 & 0.13 & 0.21 & 0.07 & Emergency response efficacy \\
\hline Access to exercise $^{2}$ & & & & & & & & & & THREAT PERCEPTIONS \\
\hline \multirow{6}{*}{$\begin{array}{l}\text { (Binary ('not sure' excluded from } \\
\text { correlation) } 0=\text { no } 1=\text { yes) }\end{array}$} & n.s. & n.s. & n.s. & n.s. & n.s. & n.s. & n.s. & n.s. & n.s. & Risk perception \\
\hline & n.s. & n.s. & n.s. & n.s. & n.s. & n.s. & n.s. & n.s. & n.s. & Worry \\
\hline & 0.05 & n.s. & 0.04 & n.s. & n.s. & 0.06 & n.s. & n.s. & n.s. & Likelihood of occurrence \\
\hline & n.s. & n.s. & n.s. & n.s. & n.s. & n.s. & n.s. & n.s. & n.s. & $\begin{array}{l}\text { COPING APPRAISALS } \\
\text { Coping capacity }\end{array}$ \\
\hline & 0.10 & 0.11 & 0.08 & 0.08 & 0.08 & 0.12 & 0.08 & 0.08 & n.s. & Cost-response capacity \\
\hline & 0.18 & 0.16 & 0.15 & 0.12 & 0.14 & 0.20 & 0.13 & 0.15 & 0.07 & Emergency response efficacy \\
\hline
\end{tabular}


Table A1. Cont.

\begin{tabular}{|c|c|c|c|c|c|c|c|c|c|c|}
\hline \multirow[t]{2}{*}{ Hazard } & \multicolumn{2}{|c|}{ Hydrogeological } & \multirow[b]{2}{*}{$\begin{array}{c}\text { Mass } \\
\text { Movements }\end{array}$} & \multicolumn{2}{|c|}{ Climate-Related } & \multirow[b]{2}{*}{ Wildfire } & \multicolumn{3}{|c|}{ Geophysical } & \\
\hline & Flood & Storm & & Heat & Frost & & Drought & Earthquake & Volcano & \\
\hline \multicolumn{11}{|l|}{ CONFIDENCE } \\
\hline Trust officials $^{2}$ & & & & & & & & & & THREAT PERCEPTIONS \\
\hline \multirow{7}{*}{ (Continuous 1-5 Likert scale) } & n.s. & n.s. & n.s. & n.s. & n.s. & n.s. & n.s. & n.s. & 0.04 & Risk perception \\
\hline & n.s. & n.s. & n.s. & n.s. & 0.06 & n.s. & n.s. & n.s. & 0.05 & Worry \\
\hline & n.s. & n.s. & n.s. & n.s. & n.s. & -0.04 & n.s. & -0.06 & -0.05 & Likelihood of occurrence \\
\hline & & & & & & & & & & COPING APPRAISALS \\
\hline & 0.11 & 0.11 & 0.12 & 0.08 & 0.07 & 0.14 & 0.08 & 0.14 & n.s. & Coping capacity \\
\hline & 0.23 & 0.22 & 0.18 & 0.17 & 0.20 & 0.21 & 0.18 & 0.19 & 0.17 & Cost-response capacity \\
\hline & 0.20 & 0.18 & 0.16 & 0.11 & 0.15 & 0.21 & 0.12 & 0.18 & 0.12 & Emergency response efficacy \\
\hline Trust sources of warning ${ }^{1}$ & & & & & & & & & & THREAT PERCEPTIONS \\
\hline \multirow{7}{*}{ (Continuous 1-5 Likert scale) } & n.s. & n.s. & 0.05 & n.s. & 0.05 & n.s. & 0.08 & na & na & Risk perception \\
\hline & 0.05 & n.s. & 0.06 & n.s. & n.s. & 0.07 & 0.05 & na & na & Worry \\
\hline & 0.05 & 0.1 & 0.08 & 0.14 & 0.13 & 0.06 & 0.1 & na & na & Likelihood of occurrence \\
\hline & & & & & & & & & & COPING APPRAISALS \\
\hline & 0.12 & 0.17 & 0.11 & 0.18 & 0.15 & 0.14 & 0.18 & na & na & Coping capacity \\
\hline & 0.19 & 0.23 & 0.21 & 0.24 & 0.28 & 0.20 & 0.21 & na & na & Cost-response capacity \\
\hline & 0.21 & 0.25 & 0.24 & 0.29 & 0.32 & 0.27 & 0.28 & na & na & Emergency response efficacy \\
\hline \multicolumn{11}{|l|}{ DEMOGRAPHICS } \\
\hline Gender & & & & & & & & & & THREAT PERCEPTIONS \\
\hline \multirow{7}{*}{$($ Ordinal $1=$ female $2=$ male $)$} & -0.14 & -0.14 & -0.14 & -0.10 & -0.14 & -0.11 & -0.08 & -0.07 & -0.04 & Risk perception \\
\hline & -0.14 & -0.12 & -0.17 & -0.05 & -0.21 & -0.13 & -0.05 & -0.10 & -0.18 & Worry \\
\hline & -0.10 & -0.05 & -0.15 & -0.06 & n.s. & -0.07 & n.s. & -0.15 & -0.06 & Likelihood of occurrence \\
\hline & & & & & & & & & & COPING APPRAISALS \\
\hline & 0.13 & 0.12 & 0.10 & 0.09 & 0.11 & 0.10 & 0.09 & n.s. & 0.09 & Coping capacity \\
\hline & 0.11 & 0.14 & 0.09 & 0.12 & 0.15 & 0.11 & 0.14 & n.s. & n.s. & Cost-response capacity \\
\hline & 0.20 & 0.23 & 0.11 & 0.10 & 0.22 & 0.20 & 0.17 & 0.12 & 0.04 & Emergency response efficacy \\
\hline Home ownership & & & & & & & & & & THREAT PERCEPTIONS \\
\hline \multirow{7}{*}{$($ Binary $0=$ no $1=$ yes $)$} & n.s. & 0.05 & -0.05 & n.s. & n.s. & -0.04 & n.s. & n.s. & -0.06 & Risk perception \\
\hline & n.s. & 0.09 & n.s. & n.s. & & n.s. & n.s. & n.s. & n.s. & Worry \\
\hline & -0.04 & -0.04 & -0.05 & n.s. & 0.09 & n.s. & n.s. & n.s. & n.s. & Likelihood of occurrence \\
\hline & & & & & & & & & & COPING APPRAISALS \\
\hline & n.s. & n.s. & n.s. & n.s. & n.s. & n.s. & n.s. & n.s. & n.s. & Coping capacity \\
\hline & 0.06 & 0.04 & n.s. & 0.06 & 0.05 & 0.04 & n.s. & n.s. & n.s. & Cost-response capacity \\
\hline & 0.07 & n.s. & n.s. & n.s. & n.s. & 0.05 & n.s. & n.s. & n.s. & Emergency response efficacy \\
\hline
\end{tabular}


Table A1. Cont.

\begin{tabular}{|c|c|c|c|c|c|c|c|c|c|c|}
\hline \multirow[t]{2}{*}{ Hazard } & \multicolumn{2}{|c|}{ Hydrogeological } & \multirow[b]{2}{*}{$\begin{array}{c}\text { Mass } \\
\text { Movements }\end{array}$} & \multicolumn{2}{|c|}{ Climate-Related } & \multirow[b]{2}{*}{ Wildfire } & \multicolumn{3}{|c|}{ Geophysical } & \\
\hline & Flood & Storm & & Heat & Frost & & Drought & Earthquake & Volcano & \multirow[b]{2}{*}{ THREAT PERCEPTIONS } \\
\hline Education level & & & & & & & & & & \\
\hline \multirow{6}{*}{$\begin{array}{c}\text { Ordinal } 1=\text { primary } 2=\text { secondary } 3 \\
=\text { technical schools } 4=\text { bachelor } 5= \\
\text { master }- \text { PhD) }\end{array}$} & n.s. & n.s. & n.s. & n.s. & -0.08 & n.s. & n.s. & n.s. & n.s. & Risk perception \\
\hline & n.s. & n.s. & -0.06 & -0.04 & -0.07 & n.s. & -0.06 & n.s. & -0.08 & Worry \\
\hline & 0.09 & 0.04 & n.s. & 0.06 & -0.07 & 0.05 & n.s. & n.s. & n.s. & $\begin{array}{l}\text { Likelihood of occurrence } \\
\text { COPING APPRAISALS }\end{array}$ \\
\hline & n.s. & n.s. & n.s. & n.s. & n.s. & n.s. & n.s. & n.s. & n.s. & Coping capacity \\
\hline & 0.17 & 0.18 & 0.14 & 0.16 & 0.13 & 0.15 & 0.10 & 0.15 & 0.09 & Cost-response capacity \\
\hline & n.s. & n.s. & n.s. & n.s. & n.s. & n.s. & n.s. & 0.10 & n.s. & Emergency response efficacy \\
\hline Income level & & & & & & & & & & THREAT PERCEPTIONS \\
\hline \multirow{6}{*}{$\begin{array}{c}\text { (Ordinal (1-4) } 1:<10,000 \text { euros } 2: \\
10,000-20,000 \text { euros } 3: \\
\text { 20,000-40,000 euros 4: }>40,000 \\
\text { euros) }\end{array}$} & -0.05 & n.s. & n.s. & -0.06 & -0.08 & n.s. & -0.05 & n.s. & n.s. & Risk perception \\
\hline & n.s. & n.s. & -0.06 & n.s. & -0.08 & -0.04 & n.s. & n.s. & -0.08 & Worry \\
\hline & n.s. & n.s. & n.s. & n.s. & -0.06 & n.s. & n.s. & n.s. & n.s. & Likelihood of occurrence \\
\hline & 0.06 & n.s. & n.s. & n.s. & n.s. & n.s. & n.s. & n.s. & n.s. & $\begin{array}{l}\text { COPING APPRAISALS } \\
\text { Coping capacity }\end{array}$ \\
\hline & 0.26 & 0.24 & 0.23 & 0.23 & 0.20 & 0.23 & 0.21 & 0.24 & 0.15 & Cost-response capacity \\
\hline & n.s. & n.s. & n.s. & n.s. & 0.04 & n.s. & 0.06 & 0.07 & n.s. & Emergency response efficacy \\
\hline Age level & & & & & & & & & & THREAT PERCEPTIONS \\
\hline \multirow{6}{*}{$\begin{array}{c}\text { (Ordinal (1-7) 1: 15-24 2: 25-34 3: } \\
35-44 \text { 4: 45-54 5: 55-64 6: 65-74 7: } \\
\text { >75) }\end{array}$} & -0.06 & 0.05 & -0.04 & 0.07 & n.s. & -0.06 & n.s. & 0.05 & -0.09 & \multirow{6}{*}{$\begin{array}{c}\text { Risk perception } \\
\text { Worry } \\
\text { Likelihood of occurrence } \\
\text { COPING APPRAISALS } \\
\text { Coping capacity } \\
\text { Cost-response capacity } \\
\text { Emergency response efficacy }\end{array}$} \\
\hline & 0.06 & 0.12 & 0.05 & 0.13 & n.s. & n.s. & 0.07 & 0.13 & -0.05 & \\
\hline & n.s. & -0.06 & -0.05 & n.s. & n.s. & n.s. & n.s. & 0.08 & 0.09 & \\
\hline & n.s. & n.s. & n.s. & n.s. & n.s. & n.s. & n.s. & n.s. & n.s. & \\
\hline & n.s. & n.s. & n.s. & n.s. & n.s. & n.s. & -0.04 & n.s. & n.s. & \\
\hline & 0.05 & n.s. & 0.05 & 0.05 & n.s. & 0.09 & n.s. & -0.05 & 0.09 & \\
\hline
\end{tabular}


Table A2. Correlations (Spearman's rho coefficient) between awareness/confidence/demographic variables and precautionary behaviors, per hazard ${ }^{1}$.

\begin{tabular}{|c|c|c|c|c|c|c|c|c|c|c|c|}
\hline & \multicolumn{2}{|c|}{ Hydrogeological } & \multicolumn{4}{|c|}{ Climate-Related } & \multirow[b]{2}{*}{ Drought } & \multicolumn{2}{|l|}{ Geophysical } & \multirow[t]{2}{*}{$\begin{array}{c}\text { All } \\
\text { Hazards }\end{array}$} & \\
\hline & Flood & Storm & $\begin{array}{c}\text { Mass } \\
\text { movement }\end{array}$ & Heat & Frost & Wildfire & & Earthquake & Volcano & & \\
\hline Variable & & & & & & & & & & & Variable \\
\hline THREAT PERCEPTIONS & & & & & & & & & & & PRECAUTIONARY BEHAVIOR \\
\hline Risk perception & 0.09 & 0.11 & 0.05 & n.s. & 0.06 & 0.09 & 0.07 & n.s. & n.s. & n.a. & Preparedness level \\
\hline Worry & 0.14 & 0.12 & 0.10 & 0.06 & 0.08 & 0.08 & 0.09 & n.s. & n.s. & n.a. & Continuous (0-9) \\
\hline Likelihood of occurrence & 0.11 & 0.06 & 0.07 & n.s. & 0.08 & 0.10 & 0.05 & n.s. & 0.05 & n.a. & (details in Section 3.4) \\
\hline COPING APPRAISALS & & & & & & & & & & & PRECAUTIONARY BEHAVIOR \\
\hline Coping capacity & 0.24 & 0.27 & 0.14 & 0.18 & 0.16 & 0.21 & 0.18 & 0.21 & n.s. & n.a. & Preparedness level \\
\hline Cost-response capacity & 0.18 & 0.17 & 0.12 & 0.15 & 0.14 & 0.17 & 0.13 & 0.14 & n.s. & n.a. & $"$ \\
\hline Emergency response efficacy & 0.30 & 0.27 & 0.24 & 0.17 & 0.18 & 0.27 & 0.22 & 0.17 & 0.12 & n.a. & $"$ \\
\hline AWARENESS & & & & & & & & & & & PRECAUTIONARY BEHAVIOR \\
\hline Disaster experience & 0.18 & 0.18 & 0.15 & 0.16 & 0.16 & 0.21 & 0.16 & 0.15 & 0.10 & n.a. & Preparedness level \\
\hline Time since last experience & -0.11 & n.s. & n.s. & n.s. & n.s. & n.s. & n.s. & n.s. & n.s. & n.a. & " \\
\hline Access to information & n.a. & n.a. & n.a. & n.a. & n.a. & n.a. & n.a. & n.a. & n.a. & 0.18 & " \\
\hline Access to emergency exercise & n.a. & n.a. & n.a. & n.a. & n.a. & n.a. & n.a. & n.a. & n.a. & 0.19 & " \\
\hline Trust in officials & n.a. & n.a. & n.a. & n.a. & n.a. & n.a. & n.a. & n.a. & n.a. & 0.10 & $"$ \\
\hline DEMOGRAPHICS & & & & & & & & & & & PRECAUTIONARY BEHAVIOR \\
\hline Gender & n.a. & n.a. & n.a. & n.a. & n.a. & n.a. & n.a. & n.a. & n.a. & 0.05 & Preparedness level \\
\hline Home ownership & n.a. & n.a. & n.a. & n.a. & n.a. & n.a. & n.a. & n.a. & n.a. & 0.16 & " \\
\hline Education & n.a. & n.a. & n.a. & n.a. & n.a. & n.a. & n.a. & n.a. & n.a. & n.s. & " \\
\hline Income & n.a. & n.a. & n.a. & n.a. & n.a. & n.a. & n.a. & n.a. & n.a. & 0.09 & " \\
\hline Age & n.a. & n.a. & n.a. & n.a. & n.a. & n.a. & n.a. & n.a. & n.a. & 0.15 & " \\
\hline THREAT PERCEPTIONS & & & & & & & & & & & PRECAUTIONARY BEHAVIOR \\
\hline Risk perception & n.s. & 0.05 & n.s. & n.s. & n.s. & n.s. & n.s. & n.s. & n.s. & n.a. & Insurance purchase (binary, $0=n o, 1=y e s)$ \\
\hline Worry & 0.05 & 0.07 & n.s. & n.s. & n.s. & n.s. & n.s. & n.s. & n.s. & n.a. & " \\
\hline Likelihood of occurrence & n.s. & n.s. & n.s. & n.s. & n.s. & n.s. & n.s. & n.s. & n.s. & n.a. & " \\
\hline COPING APPRAISALS & & & & & & & & & & & PRECAUTIONARY BEHAVIOR \\
\hline Coping capacity & 0.07 & 0.05 & n.s. & 0.08 & n.s. & n.s. & 0.06 & 0.11 & n.s. & n.a. & Insurance purchase \\
\hline Cost-response capacity & 0.11 & 0.10 & 0.08 & 0.10 & 0.08 & 0.10 & 0.07 & 0.12 & 0.07 & n.a. & " \\
\hline $\begin{array}{l}\text { Emergency response efficacy } \\
\text { AWARENESS }\end{array}$ & n.s. & n.s. & n.s. & n.s. & n.s. & n.s. & n.s. & n.s. & n.s. & n.a. & " \\
\hline Disaster experience & n.s. & n.s. & n.s. & n.s. & n.s. & n.s. & n.s. & n.s. & n.s. & n.a. & Insurance purchase \\
\hline Time since last experience & n.s. & n.s. & n.s. & n.s. & n.s. & n.s. & n.s. & n.s. & n.s. & n.a. & " \\
\hline Access to information & n.a. & n.a. & n.a. & n.a. & n.a. & n.a. & n.a. & n.a. & n.a. & n.s. & $"$ \\
\hline Access to emergency exercise & n.a. & n.a. & n.a. & n.a. & n.a. & n.a. & n.a. & n.a. & n.a. & n.s. & $"$ \\
\hline Trust in officials & n.a. & n.a. & n.a. & n.a. & n.a. & n.a. & n.a. & n.a. & n.a. & n.s. & $"$ \\
\hline DEMOGRAPHICS & & & & & & & & & & & PRECAUTIONARY BEHAVIOR \\
\hline Gender & n.a. & n.a. & n.a. & n.a. & n.a. & n.a. & n.a. & n.a. & n.a. & n.s. & Insurance purchase \\
\hline Home ownership & n.a. & n.a. & n.a. & n.a. & n.a. & n.a. & n.a. & n.a. & n.a. & 0.20 & $" 1$ \\
\hline Education & n.a. & n.a. & n.a. & n.a. & n.a. & n.a. & n.a. & n.a. & n.a. & 0.06 & $"$ \\
\hline Income & n.a. & n.a. & n.a. & n.a. & n.a. & n.a. & n.a. & n.a. & n.a. & 0.19 & $"$ \\
\hline Age & n.a. & n.a. & n.a. & n.a. & n.a. & n.a. & n.a. & n.a. & n.a. & 0.13 & " \\
\hline
\end{tabular}




\section{References}

1. Barredo, J.I. Normalised flood losses in Europe: 1970-2006. Nat. Hazards Earth Syst. Sci. 2009, 9, 97-104. [CrossRef]

2. Merz, B.; Kreibich, H.; Schwarze, R.; Thieken, A. Review article "Assessment of economic flood damage". Nat. Hazards Earth Syst. Sci. 2010, 10, 1697-1724. [CrossRef]

3. Petersen, M.S. Impacts of flash floods. In Coping with Flash Floods; Gruntfest, E., Handmer, J., Eds.; Springer: Dordrecht, The Netherlands, 2001; Volume 77, pp. 11-13. [CrossRef]

4. Kotlyakov, V.M.; Desinov, L.V.; Dolgov, S.V.; Koronkevich, N.I.; Likhacheva, E.A.; Makkaveev, A.N.; Rudakov, V.A. Flooding of July 6-7, 2012, in the town of Krymsk. Reg. Res. Russ. 2013, 3, 32-39. [CrossRef]

5. Lopez Bustos, A.; Coll, J.M.; Llansó, J.M.; Espinoza, R. Resumen y Conclusiones de los Estudios Sobre las Avenidas del Vallés en 1962; Technical Report; Instituto de Hidrología: Madrid, Spain, 1964.

6. Diakakis, M.; Deligiannakis, G.; Katsetsiadou, K.; Lekkas, E. Hurricane Sandy mortality in the Caribbean and continental North America. Disaster Prev. Manag. 2015, 24, 132-148. [CrossRef]

7. Rappaport, E.N. Fatalities in the United States from Atlantic Tropical Cyclones: New Data and Interpretation. Bull. Am. Meteorol. Soc. 2014, 95, 341-346. [CrossRef]

8. Jonkman, S.N.; Kelman, I. An analysis of the causes and circumstances of flood disaster deaths. Disasters 2005, 29, 75-97. [CrossRef]

9. Petrucci, O.; Papagiannaki, K.; Aceto, L.; Boissier, L.; Kotroni, V.; Grimalt, M.; Llasat, M.C.; Llasat-Botija, M.; Rosselló, J.; Pasqua, A.A.; et al. MEFF: The database of MEditerranean Flood Fatalities (1980 to 2015). J. Flood Risk Manag. 2019, 12, e12461. [CrossRef]

10. Molina-Terrén, D.M.; Xanthopoulos, G.; Diakakis, M.; Ribeiro, L.; Caballero, D.; Delogu, G.M.; Viegas, D.X.; Silva, C.A.; Cardil, A. Analysis of forest fire fatalities in Southern Europe: Spain, Portugal, Greece and Sardinia (Italy). Int. J. Wildland Fire 2019, 28, 85-98. [CrossRef]

11. Wallemacq, P.; House, R. Economic Losses, Poverty \& Disasters: 1998-2017; Centre for Research on the Epidemiology of Disasters (CRED): Brussels, Belgium, 2018.

12. Alfieri, L.; Burek, P.; Feyen, L.; Forzieri, G. Global warming increases the frequency of river floods in Europe. Hydrol. Earth Syst. Sci. 2015, 19, 2247-2260. [CrossRef]

13. Flannigan, M.D.; Stocks, B.J.; Wotton, B.M. Climate change and forest fires. Sci. Total Environ. 2000, 262, 221-229. [CrossRef]

14. Gariano, S.L.; Guzzetti, F. Landslides in a changing climate. Earth Sci. Rev. 2016, 162, 227-252. [CrossRef]

15. Kreibich, H.; Bubeck, P.; Van Vliet, M.; De Moel, H. A review of damage-reducing measures to manage fluvial flood risks in a changing climate. Mitig. Adapt. Strateg. Glob. Chang. 2015, 20, 967-989. [CrossRef]

16. Cloke, H.L.; Pappenberger, F. Ensemble flood forecasting: A review. J. Hydrol. 2009, 375, 613-626. [CrossRef]

17. Yuan, C.; Zhang, Y.; Liu, Z. A survey on technologies for automatic forest fire monitoring, detection, and fighting using unmanned aerial vehicles and remote sensing techniques. Can. J. For. Res. 2015, 45, 783-792. [CrossRef]

18. Choubin, B.; Moradi, E.; Golshan, M.; Adamowski, J.; Sajedi-Hosseini, F.; Mosavi, A. An ensemble prediction of flood susceptibility using multivariate discriminant analysis, classification and regression trees, and support vector machines. Sci. Total Environ. 2019, 651, 2087-2096. [CrossRef]

19. Teng, J.; Jakeman, A.J.; Vaze, J.; Croke, B.F.W.; Dutta, D.; Kim, S. Flood inundation modelling: A review of methods, recent advances and uncertainty analysis. Environ. Model. Softw. 2017, 90, 201-216. [CrossRef]

20. Mosavi, A.; Ozturk, P.; Chau, K. Flood Prediction Using Machine Learning Models: Literature Review. Water 2018, 10, 1536. [CrossRef]

21. Forzieri, G.; Feyen, L.; Russo, S.; Vousdoukas, M.; Alfieri, L.; Outten, S.; Migliavacca, M.; Bianchi, A.; Rojas, R.; Cid, A. Multi-hazard assessment in Europe under climate change. Clim. Chang. 2016, 137, 105-119. [CrossRef]

22. Hunt, A.; Watkiss, P. Climate change impacts and adaptation in cities: A review of the literature. Clim. Chang. 2011, 104, 13-49. [CrossRef]

23. Svenson, O. On expert judgements in safety analyses in the process industries. Reliab. Eng. Syst. Saf. 1989, 25, 219-256. [CrossRef]

24. Brilly, M.; Polic, M. Public perception of flood risks, flood forecasting and mitigation. Nat. Hazards Earth Syst. Sci. 2005, 5, 345-355. [CrossRef] 
25. Botzen, W.J.W.; Aerts, J.C.J.H.; van den Bergh, J.C.J.M. Willingness of homeowners to mitigate climate risk through insurance. Ecol. Econ. 2009, 68, 2265-2277. [CrossRef]

26. Shaw, R.; Shiwaku, K.; Kobayashi, H.K.; Kobayashi, M. Linking experience, education, perception and earthquake preparedness. Disaster Prev. Manag. 2004, 13, 39-49. [CrossRef]

27. Perry, R.W.; Lindell, M.K. Volcanic risk perception and adjustment in a multi-hazard environment. J. Volcanol. Geotherm. Res. 2008, 172, 170-178. [CrossRef]

28. Kung, Y.-W.; Chen, S.-H. Perception of Earthquake Risk in Taiwan: Effects of Gender and Past Earthquake Experience. Risk Anal. 2012, 32, 1535-1546. [CrossRef]

29. Beck, U. Risk Society: Towards a New Modernity, 1st ed.; Sage: California, CA, USA, 1992.

30. Bubeck, P.; Botzen, W.J.W.; Aerts, J.C.J.H. A Review of Risk Perceptions and Other Factors that Influence Flood Mitigation Behavior. Risk Anal. 2012, 32, 1481-1495. [CrossRef]

31. Kellens, W.; Terpstra, T.; De Maeyer, P. Perception and Communication of Flood Risks: A Systematic Review of Empirical Research. Risk Anal. 2013, 33, 24-49. [CrossRef]

32. Armaş, I.; Avram, E. Perception of flood risk in Danube Delta, Romania. Nat. Hazards 2009, 50, $269-287$. [CrossRef]

33. Martens, T.; Garrelts, H.; Grunenberg, H.; Lange, H. Taking the heterogeneity of citizens into account: Flood risk communication in coastal cities-A case study of Bremen. Nat. Hazards Earth Syst. Sci. 2009, 9, 1931-1940. [CrossRef]

34. López-Marrero, T.; Yarnal, B. Putting adaptive capacity into the context of people's lives: A case study of two flood-prone communities in Puerto Rico. Nat. Hazards 2010, 52, 277-297. [CrossRef]

35. Hung, H.C. The attitude towards flood insurance purchase when respondents' preferences are uncertain: A fuzzy approach. J. Risk Res. 2009, 12, 239-258. [CrossRef]

36. Kellens, W.; Zaalberg, R.; Neutens, T.; Vanneuville, W.; De Maeyer, P. An Analysis of the Public Perception of Flood Risk on the Belgian Coast. Risk Anal. 2011, 31, 1055-1068. [CrossRef]

37. Pagneux, E.; Gísladóttir, G.; Jónsdóttir, S. Public perception of flood hazard and flood risk in Iceland: A case study in a watershed prone to ice-jam floods. Nat. Hazards 2011, 58, 269-287. [CrossRef]

38. Hammond, M.J.; Chen, A.S.; Djordjević, S.; Butler, D.; Mark, O. Urban flood impact assessment: A state-of-the-art review. Urban Water J. 2015, 12, 14-29. [CrossRef]

39. Cole, S.J.; Moore, R.J.; Wells, S.C.; Mattingley, P.S. Real-time forecasts of flood hazard and impact: Some UK experiences. E3S Web Conf. 2016, 7, 18015. [CrossRef]

40. Papagiannaki, K.; Kotroni, V.; Lagouvardos, K.; Papagiannakis, G. How awareness and confidence affect flood-risk precautionary behavior of Greek citizens: The role of perceptual and emotional mechanisms. Nat. Hazards Earth Syst. Sci. 2019, 19, 1329-1346. [CrossRef]

41. Terpstra, T.; Lindell, M.K. Citizens' Perceptions of Flood Hazard Adjustments. Environ. Behav. 2013, 45, 993-1018. [CrossRef]

42. Becker, J.S.; Taylor, H.L.; Doody, B.J.; Wright, K.C.; Gruntfest, E.; Webber, D. A Review of People's Behavior in and around Floodwater. Weather Clim. Soc. 2015, 7, 321-332. [CrossRef]

43. Lo, A.Y. The role of social norms in climate adaptation: Mediating risk perception and flood insurance purchase. Glob. Environ. Chang. 2013, 23, 1249-1257. [CrossRef]

44. Poussin, J.K.; Botzen, W.J.W.; Aerts, J.C.J.H. Factors of influence on flood damage mitigation behaviour by households. Environ. Sci. Policy 2014, 40, 69-77. [CrossRef]

45. Slovic, P.; Finucane, M.L.; Peters, E.; MacGregor, D.G. The affect heuristic. Eur. J. Oper. Res. 2007, 177, 1333-1352. [CrossRef]

46. Keller, C.; Siegrist, M.; Gutscher, H. The Role of the Affect and Availability Heuristics in Risk Communication. Risk Anal. 2006, 26, 631-639. [CrossRef]

47. Siegrist, M.; Gutscher, H. Natural Hazards and Motivation for Mitigation Behavior: People Cannot Predict the Affect Evoked by a Severe Flood. Risk Anal. 2008, 28, 771-778. [CrossRef]

48. Terpstra, T.; Gutteling, J.M. Households' Perceived Responsibilities in Flood Risk Management in The Netherlands. Int. J. Water Resour. Dev. 2008, 24, 555-565. [CrossRef]

49. Smith, K. Environmental Hazards: Assessing Risk and Reducing Disaster, 6th ed.; Routledge: London, UK, 2003.

50. Basolo, V.; Steinberg, L.J.; Burby, R.J.; Levine, J.; Cruz, A.M.; Huang, C. The Effects of Confidence in Government and Information on Perceived and Actual Preparedness for Disasters. Environ. Behav. 2009, 41, 338-364. [CrossRef] 
51. Walsh-Daneshmandi, A.; Maclachlan, M. Environmental risk to the self: Factor analysis and development of subscales for the environmental appraisal inventory (EAI) with an Irish sample. J. Environ. Psychol. 2000, 20, 141-149. [CrossRef]

52. Lindell, M.K.; Hwang, S.N. Households' Perceived Personal Risk and Responses in a Multihazard Environment. Risk Anal. 2008, 28, 539-556. [CrossRef]

53. Sullivan-Wiley, K.A.; Short Gianotti, A.G. Risk Perception in a Multi-Hazard Environment. World Dev. 2017, 97, 138-152. [CrossRef]

54. Diakakis, M.; Priskos, G.; Skordoulis, M. Public perception of flood risk in flash flood prone areas of Eastern Mediterranean: The case of Attica Region in Greece. Int. J. Disaster Risk Reduct. 2018, 28, 404-413. [CrossRef]

55. Lagouvardos, K.; Kotroni, V.; Koussis, A.; Feidas, H.; Buzzi, A.; Malguzzi, P. The Meteorological Model BOLAM at the National Observatory of Athens: Assessment of Two-Year Operational Use. J. Appl. Meteorol. 2003, 42, 1667-1678. [CrossRef]

56. Giannaros, T.M.; Kotroni, V.; Lagouvardos, K. Predicting lightning activity in Greece with the Weather Research and Forecasting (WRF) model. Atmos. Res. 2015, 156, 1-13. [CrossRef]

57. Flaounas, E.; Kotroni, V.; Lagouvardos, K.; Klose, M.; Flamant, C.; Giannaros, T. Sensitivity of the WRF-Chem model to different dust emission parametrisation: Assessment in the broader Mediterranean region. Geosci. Model Dev. 2017, 10, 2925-2945. [CrossRef]

58. Lagouvardos, K.; Kotroni, V.; Bezes, A.; Koletsis, I.; Kopania, T.; Lykoudis, S.; Mazarakis, N.; Papagiannaki, K.; Vougioukas, S. The automatic weather stations NOANN network of the National Observatory of Athens: Operation and database. Geosci. Data J. 2017, 4, 4-16. [CrossRef]

59. Papagiannaki, K.; Kotroni, V.; Lagouvardos, K.; Ruin, I.; Bezes, A. Urban Area Response to Flash Flood-Triggering Rainfall, Featuring Human Behavioral Factors: The Case of 22 October 2015 in Attica, Greece. Weather Clim. Soc. 2017, 9, 621-638. [CrossRef]

60. McDonald, J.H. Handbook of Biological Statistics, 3rd ed.; Sparky House Publishing: Baltimore, MD, USA, 2014; Available online: http://www.biostathandbook.com/ (accessed on 29 July 2019).

61. Shipley, B. Cause and Correlation in Biology: A User's Guide to Path Analysis, Structural Equations and Causal Inference with R, 2nd ed.; Cambridge University Press: Cambridge, UK, 2016. [CrossRef]

62. Sniezek, J.A.; Buckley, T. Confidence depends on level of aggregation. J. Behav. Decis. Mak. 1991, 4, $263-272$. [CrossRef]

63. Rogers, R.W. Cognitive and physiological processes in fear appeals and attitude change: A revised theory of protection motivation. In Social Psychophysiology; Cacioppo, J., Petty, R., Eds.; Guilford Press: New York, NY, USA, 1983.

64. Terpstra, T. Emotions, Trust, and Perceived Risk: Affective and Cognitive Routes to Flood Preparedness Behavior. Risk Anal. 2011, 31, 1658-1675. [CrossRef] [PubMed]

65. Grothmann, T.; Reusswig, F. People at Risk of Flooding: Why Some Residents Take Precautionary Action While Others Do Not. Nat. Hazards 2006, 38, 101-120. [CrossRef]

66. Alexander, D.E. The L'Aquila Earthquake of 6 April 2009 and Italian Government Policy on Disaster Response. J. Nat. Resour. Policy Res. 2010, 2, 325-342. [CrossRef]

67. Papadopoulos, I.N.; Kanakaris, N.; Triantafillidis, A.; Stefanakos, J.; Kainourgios, A.; Leukidis, C. Autopsy findings from 111 deaths in the 1999 Athens earthquake as a basis for auditing the emergency response. BJS 2004, 91, 1633-1640. [CrossRef]

68. Tural, Ü.; Coşkun, B.; Önder, E.; Çorapçioğlu, A.; Yildiz, M.; Kesepara, C.; Karakaya, I.; Aydin, M.; Erol, A.; Torun, F.; et al. Psychological consequences of the 1999 earthquake in Turkey. J. Trauma. Stress 2004, 17, 451-459. [CrossRef]

69. Papazachos, V.; Papazachos, B.; Papazachou, C.; Papazachou, K. The Earthquakes of Greece; Editions Ziti: Athens, Greece, 1997.

70. Giardini, D.; Jimenez, M.J.; Grunthal, G. European-Mediterranean Seismic Hazard Map. Scale 1:5000000. International Geological Correlation Program; Project no 382: SESAME; European Seismological Commission: Brussels, Belgium, 2003.

71. Slovic, P.; Fischhoff, B.; Lichtenstein, S. Why Study Risk Perception? Risk Anal. 1982, 2, 83-93. [CrossRef]

72. Slovic, P. Perception of risk. Science 1987, 236, 280-285. [CrossRef] [PubMed]

73. Diakakis, M.; Xanthopoulos, G.; Gregos, L. Analysis of forest fire fatalities in Greece: 1977-2013. Int. J. Wildland Fire 2016, 25, 797-809. [CrossRef] 
74. Tsaliki, L. Technologies of Political Mobilization and Civil Society in Greece: The Wildfires of Summer 2007. Convergence 2010, 16, 151-161. [CrossRef]

75. Diakakis, M. Have flood mortality qualitative characteristics changed during the last decades? The case study of Greece. Environ. Hazards 2016, 15, 148-159. [CrossRef]

76. Diakakis, M.; Mavroulis, S.; Deligiannakis, G. Floods in Greece, a statistical and spatial approach. Nat. Hazards 2012, 62, 485-500. [CrossRef]

77. Papagiannaki, K.; Lagouvardos, K.; Kotroni, V. A database of high-impact weather events in Greece: A descriptive impact analysis for the period 2001-2011. Nat. Hazards Earth Syst. Sci. 2013, 13, 727-736. [CrossRef]

78. Gaume, E.; Borga, M.; Llassat, M.C.; Maouche, S.; Lang, M.; Diakakis, M. Mediterranean extreme floods and flash floods. In The Mediterranean Region under Climate Change. A Scientific Update; IRD Editions: Paris, France, 2016; pp. 133-144.

79. Becker, J.S.; Paton, D.; Johnston, D.M.; Ronan, K.R.; McClure, J. The role of prior experience in informing and motivating earthquake preparedness. Int. J. Disaster Risk Reduct. 2017, 22, 179-193. [CrossRef]

80. Miceli, R.; Sotgiu, I.; Settanni, M. Disaster preparedness and perception of flood risk: A study in an alpine valley in Italy. J. Environ. Psychol. 2008, 28, 164-173. [CrossRef]

81. Altarawneh, L.; Mackee, J.; Gajendran, T. The influence of cognitive and affective risk perceptions on flood preparedness intentions: A dual-process approach. Procedia Eng. 2018, 212, 1203-1210. [CrossRef]

82. Slovic, P.; Finucane, M.L.; Peters, E.; MacGregor, D.G. Risk as Analysis and Risk as Feelings: Some Thoughts about Affect, Reason, Risk, and Rationality. Risk Anal. 2004, 24, 311-322. [CrossRef]

83. Thieken, A.H.; Petrow, T.; Kreibich, H.; Merz, B. Insurability and Mitigation of Flood Losses in Private Households in Germany. Risk Anal. 2006, 26, 383-395. [CrossRef]

84. Rüstemli, A.; Karanci, A.N. Correlates of Earthquake Cognitions and Preparedness Behavior in a Victimized Population. J. Soc. Psychol. 1999, 139, 91-101. [CrossRef]

85. Lindell, M.K.; Whitney, D.J. Correlates of household seismic hazard adjustment adoption. Risk Anal. 2000, 20, 13-25. [CrossRef]

86. Kreibich, H.; Thieken, A.H.; Petrow, T.; Müller, M.; Merz, B. Flood loss reduction of private households due to building precautionary measures-lessons learned from the Elbe flood in August 2002. Nat. Hazards Earth Syst. Sci. 2005, 5, 117-126. [CrossRef]

87. Sjöberg, L. The Allegedly Simple Structure of Experts' Risk Perception: An Urban Legend in Risk Research. Sci. Technol. Hum. Values 2002, 27, 443-459. [CrossRef]

88. Zaalberg, R.; Midden, C.; Meijnders, A.; McCalley, T. Prevention, Adaptation, and Threat Denial: Flooding Experiences in the Netherlands. Risk Anal. 2009, 29, 1759-1778. [CrossRef] 